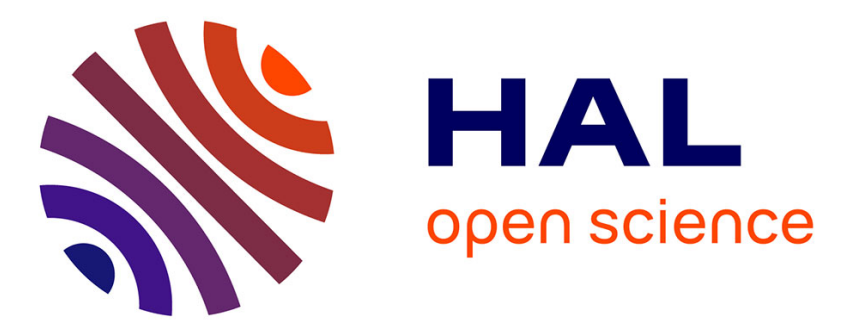

\title{
Mechanism and analyses for extracting photosynthetic electrons using exogenous quinones - what makes a good extraction pathway?
}

G. Longatte, F. Rappaport, F.-A Wollman, Manon Guille-Collignon, F. Lemaître

\section{To cite this version:}

G. Longatte, F. Rappaport, F.-A Wollman, Manon Guille-Collignon, F. Lemaître. Mechanism and analyses for extracting photosynthetic electrons using exogenous quinones - what makes a good extraction pathway?. Photochemical \& Photobiological Sciences , 2016, 15 (8), pp.969-979. 10.1039/C6PP00076B . hal-01677380

\section{HAL Id: hal-01677380 \\ https://hal.sorbonne-universite.fr/hal-01677380}

Submitted on 8 Jan 2018

HAL is a multi-disciplinary open access archive for the deposit and dissemination of scientific research documents, whether they are published or not. The documents may come from teaching and research institutions in France or abroad, or from public or private research centers.
L'archive ouverte pluridisciplinaire HAL, est destinée au dépôt et à la diffusion de documents scientifiques de niveau recherche, publiés ou non, émanant des établissements d'enseignement et de recherche français ou étrangers, des laboratoires publics ou privés. 


\title{
Mechanism and Analyses for Extracting Photosynthetic Electrons using Exogenous Quinones - What Makes a Good Extraction Pathway?
}

\author{
G. Longatte, ${ }^{a, b, c}$ F. Rappaport, ${ }^{d}+$ F.-A. Wollman, ${ }^{d}$ Manon Guille-Collignon ${ }^{a, b}$ and F. Lemaître ${ }^{a, b *}$
}

Plants or algae take many benefits from oxygenic photosynthesis by converting the solar energy into a chemical one through the synthesis of carbohydrates from carbon dioxide and water. However, the overall yield of this process is rather low (about $4 \%$ of the total energy available from sunlight is converted into chemical energy). This is principally why many works were recently devoted to the extraction of photosynthetic electrons in order to produce a sustainable electrical current. Practically, the electron transfer occurs between the photosynthetic organism and an electrode and can be assisted by the mean of an exogenous mediator, mainly a quinone. In this respect, we recently reported on a method involving fluorescence measurements to estimate the ability of different quinones to extract photosynthetic electrons from a mutant of Chlamydomonas reinhardtii. In the present work, we use the same kind of methodology to establish a zone diagram to predict the most adapted experimental conditions to extract photoelectrons from intact algae (quinone concentration, light intensity) as a function of the purpose. This will provide further insights on the extraction mechanism of photosynthetic electrons by exogenous quinones. Indeed fluorescence measurements allowed us to model the capacity of photosynthetic algae to donate electrons to an exogenous quinone by considering a numerical parameter called "open centers ratio" which is related to the Photosystem II acceptor redox state. Then using it as a proxy for investigating the extraction of photosynthetic electrons by the mean of an exogenous quinone, 2,6-DCBQ, we suggest a two steps mechanism that was globally found consistent with the experimental extracted parameters.

\section{Introduction}

Extraction of photosynthetic electrons to produce an amenable electrical current is a recent and important research topic. Indeed photosynthesis (Figure 1 ) has an overall low yield in vivo (a few $\%$ of the total energy available from sunlight being converted into chemical energy). Among various limitations, such a low yield is related to the saturation of the photochemical conversion (rate limiting electron transfer steps occurring downstream of the Photosystem II) but not to the quantum efficiencies of photosystems (close to $100 \%$ under optimal conditions). ${ }^{1}$ This is why photosynthesis is viewed as a promising and unexploited reservoir to produce electricity by harvesting electrons among the

a. Ecole normale supérieure, PSL Research University, UPMC Univ Paris 06, CNRS, Département de Chimie, PASTEUR, 24, rue Lhomond, 75005 Paris, France. b. Sorbonne Universités, UPMC Univ Paris 06, ENS, CNRS, PASTEUR, 75005 Paris, France.

c. Current address: School of Chemistry, The University of New South Wales, Sydney, NSW 2052, Australia.

d. Laboratoire de physiologie membranaire et moléculaire du chloroplaste, CNRS, UPMC UMR 7141, I.B.PC., 13 rue Pierre et Marie Curie, 75005 Paris, France.

+ F.Rappaport deceased before completion of this manuscript. His co-authors wish to dedicate this article to his memory.

* Corresponding author. email: frederic.lemaitre@ens.fr photosynthetic chain. Furthermore, under high light conditions, the saturation of the photochemical conversion can lead to photoinhibition, i.e. the formation of reactive species which can induce some biological damages while overwhelming the usual photorepair pathways. ${ }^{2}$ Therefore, extracting photosynthetic electrons is expected to alleviate the saturation and thus to limit photoinhibition.

Several strategies for harvesting photosynthetic electrons have been implemented over recent years. Although all involve obviously an electrode for collecting the electrons from the photosynthetic organism, the nature of the biological target and the experimental conditions are rather various. For instance, thylakoid membranes can be immobilized on the working electrode in order to perform a direct electron transfer. ${ }^{3,}{ }^{4}$ In that case, using a redox polymer, nanoparticles or nanotubes has been demonstrated to help the photosynthetic electrons shuttle from the photosynthetic chain to the electrode. ${ }^{5-7}$ Alternatively, isolated Photosystems can be grafted on the electrode surface. Here again, the electron transfer could be achieved through conducting or redox polymers. ${ }^{8-11}$ It is worth mentioning that photocurrent production from photosynthesis is not restricted to isolated photosynthetic units. As an example, promising photocurrents can be also obtained with intact biological systems like cyanobacteria ${ }^{12-16}$ or green algae. ${ }^{17}$ It has also to be emphasized that more complex systems like plants were recently considered as an encouraging approach. ${ }^{18,} 19$ 
Among all these strategies, exogenous redox mediators can be subsequently involved as electron carriers to improve the electron transfer and thus giving rise to higher current densities. Hence, the oxidised form would be devoted to short-circuit the electron transfer by extracting the electrons while its reduced form would deliver them by its oxidation at the electrode surface. Within this context, exogenous quinones are often used to enhance extraction of photosynthetic electrons from isolated thylakoid membranes ${ }^{5}$ as well as from intact cells. ${ }^{20-23}$ In a previous study based on fluorescence measurements, we characterized the ability of several quinones to extract photosynthetic electrons from Photosystem II (PSII) in a mutant strain of Chlamydomonas Reinhardtii which lacks the cytochrome $b_{6} f$ complexes ( $b_{6} f$ mutant), thus being unefficient to utilize electrons photoproduced by Photosystem II. ${ }^{24} \mathrm{We}$ estimated the extraction efficiency of several exogenous quinones and provided evidence for a limitation in the availability of quinones due to their partition between intracellular membranes and other aqueous compartments. In the present work, we further analyze the effect of light intensity and quinones concentration with respect to our modeling of extraction of photosynthetic electrons by exogenous quinones. This led us to establish a zone diagram aimed at a definition of the most appropriated experimental conditions to extract photoelectrons from intact algae according to the purpose of the study.

\section{Results and discussion}

PSIl-controlled fluorescence changes were monitored in a suspension of Chlamydomonas reinhardtii cells from a mutant, $\Delta$ petA, which lacks the $b_{6} f$ complex. ${ }^{24}$ Several quinones $(1,4-$ benzoquinone (BQ), 1,4-naphtoquinone (NQ), 2,6dichlorobenzoquinone (2,6-DCBQ), 2,5-dichlorobenzoquinone (2,5$\mathrm{DCBQ}), \quad$ 2,6-dimethylbenzoquinone (2,6-DMBQ), 2,5dimethylbenzoquinone (2,5-DMBQ), p-phenylbenzoquinone (PPBQ)) were thus benchmarked for their capability to extract electrons downstream the photosystem II. However, both the effect of quinone concentration and of light intensity on the efficiency of electron extraction needs to be carefully assessed in order to better understand the mechanism and set up the proper conditions for future electrochemical harvesting. To this end, we used fluorescence experiments to determine the proportion of open reaction centers (Figure 2)..$^{24}$ Briefly, an open Photosystem II reaction center corresponds to a moiety in which the primary quinone electron acceptor $Q_{A}$ is in its oxidized state (Figure 3). ${ }^{25}$ Therefore, it can be involved in a charge separation. Conversely, a closed reaction center is related to structures where $Q_{A}$ is reduced in $Q_{A}^{-}$(Figure 3). The open centers ratio (defined here as $\Phi$ ) can be calculated from the fluorescence measurements by equation (1): ${ }^{24}$ 26

$$
\Phi=\frac{\max -F_{\text {stat }}^{\prime}}{F_{\text {max }}^{\prime}-F_{0}^{\prime}}
$$

It is worth mentioning that $\Phi$ is a good proxy for evaluating the ability of a given exogenous quinone to remove electrons from $Q_{A}{ }^{-}$ Thus, the more efficient the extraction the closer to 1 are $\Phi$ values.
Light intensity effect on the electron extraction by exogenous quinones

Fluorescence experiments were performed using an exogenous quinone (2,6-DCBQ) whose ability to accept photosynthetic electrons was previously established. ${ }^{24}$ Variations in the open centers ratio can be displayed as a function of the available quinone concentration, $C_{Q}$ (i.e. the difference between the introduced quinone concentration and the sequestered one in other cell compartments; see reference ${ }^{24}$ for more details) for five light intensities $\left(56 ; 135 ; 340 ; 800\right.$ and $1500 \mu \mathrm{E} . \mathrm{m}^{-2} . \mathrm{s}^{-1}$; see Figure 4).

As expected, the open centers ratio, and thus the electron extraction, strongly depends on the light intensity. Expectedly, it significantly increases when decreasing light intensity since $\Phi$ can be viewed as a yield resulting from the two opposite reactions occurring during the illumination, i.e. the light-induced formation of closed reaction centers through the $Q_{A}$ reduction and their reoxidation by exogenous (or endogenous) quinones. Therefore, a higher incident light will increase the number of closed reaction centers and thus will decrease $\Phi$ values. By considering that the extraction yield corresponds to Michaelis-Menten like kinetics, all the graphs displaying $\Phi$ as a function of $C_{Q}$ can be fitted and show a good agreement with the following equation:

$$
\Phi=\frac{\Phi_{0} \frac{\Phi_{\infty}}{\rho_{0}}+\Phi_{\infty} C_{Q}}{\frac{\Phi_{\infty}}{\rho_{0}}+C_{Q}}
$$

If considering Figure $4, \Phi_{\infty}$ is the open centers ratio value reached at infinite quinone concentration and $\rho_{0}$ the initial slope of the exogenous flow part of the curve displaying $\Phi$ as a function of $C_{Q}$. It has to be emphasized that despite the absence of $b_{6} f$ complex in the mutant investigated here, a residual endogenous electron flux can still occur. ${ }^{24}$ As a consequence, the open reaction centers ratio is not zero in absence of exogenous quinones (particularly at low excitation intensities ${ }^{24}$ ) and the corresponding value will be defined as $\Phi_{0}$. The values of $\Phi_{0}, \Phi_{\infty}$ and $\rho_{0}$ can thus be extracted and are grouped together in Table 1.

Because $\Phi_{0}$ is the open centers ratio in absence of exogenous quinones under a given irradiation, it corresponds to the endogenous flow yield for the PSII acceptors reoxidation. When $\Phi_{0}$ is close to 0 there are no open centers, meaning that the closed centers reoxidation rate due to the endogenous flow is lower than the open centers reduction rate due to irradiation. Conversely, if $\Phi_{0}$ is close to 1 , there are no closed centers meaning that the open centers reduction kinetics due to irradiation is much slower than the closed centers reoxidation kinetics due to the endogenous flow. Table 1 indicates very low $\Phi_{0}$ values according to the absence of $b_{6} f$ complex in the mutant (see above). Moreover, the light intensity alters the $\Phi_{0}$ values. The higher the incident light the lower the $\Phi_{0}$ values in agreement with an increased number of closed centers due to the illumination.

Because $\Phi_{\infty}$ is the maximum open centers ratio under a given irradiation, it corresponds to the maximum exogenous flow yield for the PSII acceptors reoxidation under these irradiation conditions. When $\Phi_{\infty}$ is close to 1 , the open centers reduction rate due to irradiation is much lower than the closed centers reoxidation rate 
due to the exogenous flow which is one of the features of an efficient extraction. The opposite comparison is made when $\Phi_{\infty}$ is close to 0 . $\rho_{0}$ corresponds to the slope from $\Phi_{0}$ to $\Phi_{\infty}$ and also allows us to assess the electron extraction. A $\rho_{0}$ value close to 0 will lead to a $\Phi$ value close to $\Phi_{0}$, i.e. in a case in which no extraction occurs even with a high exogenous quinones concentration. Conversely, when $\rho_{0} \rightarrow \infty$, the $\Phi$ value will be close to its maximum $\Phi_{\infty}$ value thus leading to a situation in which even quiet low exogenous concentrations leads to an efficient extraction. Both $\Phi_{\infty}$ and $\rho_{0}$ values also decrease with increasing light intensity, in accordance with a reduced number of open centers due to a more intense illumination. Finally, the extraction efficiency can be modified by means of quinone concentration or light intensity. We found no experimental condition that would preserve a full oxidation of PSII centers, even at high quinone concentration. It thus raises the question of the most appropriate conditions for performing harvesting of photosynthetic electrons.

\section{Definition of a mechanism for the electron extraction by exogenous quinones}

In order to use our experimental data to predict the most adapted conditions of extraction, we propose to consider the simple mechanism depicted in Figure 5. $\mathrm{Q}_{A}^{-}$is viewed as the main target of exogenous quinones that would compete with the natural plastoquinone secondary acceptor within the $Q_{B}$ pocket. $^{27-33}$. Due to the high affinity for the quinones investigated in this work (DCBQ and $P P B Q$, see below) with the $Q_{B}$ pocket, ${ }^{31,34-36}$ an electron exchange between the exogenous quinone and the plastoquinone pool will not be considered in the mechanism proposed here while it cannot be totally excluded.

Therefore, the proposed model is based on the electronic transfer between $Q_{A}{ }^{-}$and the exogenous quinone $Q$ according to :

$$
Q_{A^{-}}+Q=Q_{A}+Q^{-}
$$

The extraction process shown in Figure $5 B$ is described in the following manner. First of all, after illumination, the photoinduced charge separation leads to formation of closed reaction centers $Q_{A^{-}}$ (with a incident light dependent rate constant $F(I)$ ). The closed center $Q_{A^{-}}$can then react in two different pathways. On the one hand, $Q_{A}^{-}$can be reoxidised through the endogenous electron flow occurring in the photosynthetic chain (with a rate constant $k_{\text {endo) }}$ ). On the other hand, $Q_{A^{-}}$can interact with the exogenous quinone $Q$ to lead to an electron transfer. Such an electron transfer requires two equilibrated steps: the reversible binding of the exogenous quinone $Q$ within the pocket ( $k_{Q}$ and $k_{-Q}$ are the forward and backward rate constants, respectively, from the $Q$ insertion within the $Q_{B}$ pocket; rate constants) and the electron transfer itself between $Q_{A}^{-}$and $Q\left(k_{e}\right.$ and $k_{-e}$ are the forward and backward electron transfer rate constants, respectively, from $Q_{A}$ to the bound exogenous quinone $Q$; due to the significant difference between $E^{\circ}$ values for $Q$ and $Q_{A^{-}}$(see below), $k_{e}$ is expected to be larger than $k_{-}$ e). The final step is the irreversible extraction due to the release of the reduced form of the exogenous quinone from the $Q_{B}$ pocket (rate constant $k_{d Q}$ ). The reoxidation of $Q_{A^{-}}$into $Q_{A}$ involving the exogenous quinone $Q$ through these three successive steps will be now referred as the exogenous flow.

At this stage, it should be pointed out that this simple one electron mechanism may give a limited scope of the whole extraction process since quinones correspond to bielectronic systems. This question will be addressed more thoroughly in a later section and the Supporting Information and only the simple one electron mechanism will be considered.

Assuming that the open centers ratio is constant when steady state fluorescence is reached, one can consider the ratios of the four redox states involved here $\left(Q_{A}, Q_{A}^{-}, Q_{A}^{-}\right.$and $\left.Q^{-} Q_{A}\right)$ as constant. Therefore if applying the quasi steady state approximation to $Q_{A^{-}}$, $\mathrm{QQ}_{A^{-}}$and $\mathrm{Q}^{-} \mathrm{Q}_{A}$, where the inputs and outputs of each state are equal, one has :

$$
\begin{gathered}
F(I)\left[Q_{A}\right]+k_{-Q}\left[Q Q_{A}^{-}\right]=\left(k_{\text {endo }}+C_{Q} k_{Q}\right)\left[Q_{A}^{-}\right] \\
k_{-e}\left[Q^{-} Q_{A}\right]+k_{Q} C_{Q}\left[Q_{A}^{-}\right]=\left(k_{e}+k_{-Q}\right)\left[Q Q_{A}^{-}\right] \\
k_{e}\left[Q Q_{A}^{-}\right]=\left(k_{-e}+k_{d Q}\right)\left[Q^{-} Q_{A}\right]
\end{gathered}
$$

The conservation of matter leads to:

$$
\left[Q_{A}\right]+\left[Q_{A}^{-}\right]+\left[Q Q_{A}^{-}\right]+\left[Q^{-} Q_{A}\right]=1
$$

Finally, if considering the open centers ratio as the $Q_{A}$ proportion, equations (4), (5), (6) and (7) give (see details in Supporting Information):

$$
\begin{aligned}
& \Phi=\left[Q_{A}\right]= \\
& \frac{k_{\text {endo }}\left(k_{Q}\left(k_{-e}+k_{d Q}\right)+k_{d Q} k_{e}\right)+k_{Q} k_{d Q} k_{e} C_{Q}}{\left(k_{\text {endo }}+F(I)\right)\left(k_{-Q}\left(k_{-e}+k_{d Q}\right)+k_{d Q} k_{e}\right)+k_{Q} C_{Q}\left(F(I)\left(k_{e}+k_{-e}+k_{d Q}\right)+k_{d Q} k_{e}\right)}
\end{aligned}
$$

\section{Experimental validation of the mechanism with 2,6-DCBQ}

Before considering the model as a tool to define the effects of experimental conditions on the photosynthetic electron extraction, the mechanism described above has to be validated by the experimental results. As described above, without any exogenous quinones $\left(C_{Q}=0\right)$, $\Phi$ should be equal to $\Phi_{0}$. Therefore equation (8) becomes:

$$
\Phi=\Phi_{0}=\frac{k_{\text {endo }}\left(k_{Q}\left(k_{-e}+k_{d Q}\right) \quad k_{d Q} k_{e}\right)}{\left(k_{\text {endo }}+F(I)\right)\left(k_{-Q}\left(k_{-e}+k_{d Q}\right)+k_{d Q} k_{e}\right)}=\frac{k_{\text {endo }}}{k_{\text {endo }}+F(I)}
$$

Therefore, one has:

$$
\frac{1}{\Phi_{0}}=1+\frac{F(I)}{k_{\text {endo }}}
$$

The mechanism leads to a linear relationship between the inverse of the open reaction centers ratio in absence of exogenous quinones and the $Q_{A}$ photoreduction rate constant $F(I)$ with an intercept with the $y$ axis equal to 1 . As displayed in Figure $6,1 / \Phi_{0}$ 
values as a function of the incident light flow $I^{\circ}$ corresponds to a straight line $\left(1 / \Phi_{0}=1.1 \times\left. 10^{-1}\right|^{\circ}+1 ; R^{2}=0.996\right.$; the value at 1500 $\mu \mathrm{E} \cdot \mathrm{m}^{-2} \cdot \mathrm{s}^{-1}$ is not taken into account due to a too low $\Phi_{0}$ value that leads to a high uncertainty). Beyond a first consistent result with the mechanism envisioned here, it suggests that $F(I)$ linearly depends on the incident light flux, thus that $Q_{A}$ reduction is controlled by light absorption and not by an intermediate step rate. Another way to validate the mechanism of electron harvesting by exogenous quinones is to consider $\Phi_{\infty}$ values. Hence, as already defined, $\Phi_{\infty}$ mathematically corresponds to $\Phi$ values at infinite quinone concentrations. So equation (8) becomes:

$$
\Phi=\Phi_{\infty}=\frac{k_{d Q} k_{e}}{F(I)\left(k_{e}+k_{-e}+k_{d Q}\right)+k_{d Q} k_{e}}
$$

Therefore, one has:

$$
\frac{1}{\Phi_{\infty}}=1+\frac{F(I)\left(k_{e}+k_{-e} \quad k_{d Q}\right)}{k_{d Q} k_{e}}
$$

As displayed in Figure 7, equation (12) is consistent with experimental results $\left(1 / \Phi_{\infty}=1+1.1 \times\left. 10^{-3}\right|^{\circ} ; R^{2}=0.996\right)$. It is worth mentioning that similar experiments with wild type algae were also achieved (see Figure $\mathbf{7}$ and Figure $\mathbf{S 1}$ in Supporting Information). In that case, the slope did not significantly change $\left(1.2 \times 10^{-3} \mathrm{~m}^{2} . \mathrm{s} . \mu \mathrm{E}^{-1}\right)$ as expected. Indeed, wild type and $b_{6} f$ mutant only differ in terms of endogenous electron flux. Since equation (12) shows that the $1 / \Phi_{\infty}$ does not depend on $k_{\text {endo, }}$, the slope values of the $1 / \Phi_{\infty}=f\left(I^{\circ}\right)$ graphs are expected to be similar regardless the considered algae. Additionally, equation (12) suggests that, following the rate limiting step at infinite quinone concentrations, the $\Phi_{\infty}$ value may be correlated to the electron transfer rate constant $k_{\mathrm{e}}$. As a consequence, it could be correlated to the difference of standard potentials between the exogenous quinone and Photosystem II reduced electron acceptor $Q_{A}^{-}$. Indeed, according to the molecular electron transfer rate law related to Marcus theory, a quadratic dependence of the rate constant logarithm as a Gibbs free energy function (which can be assumed as the reaction driving force) is expected, as shown in equation (13).

$$
\log (k)=\log \left(k_{e}^{\Delta_{,} G^{\circ}=0}\right)-\frac{\Delta_{r} G^{\circ}}{2 R T}-\frac{\left(\Delta_{r} G^{\circ}\right)^{2}}{4 \lambda R T}
$$

$\lambda$ is the system reorganization energy, that corresponds to the energy which would have to be provided to put reactant into the products configuration (bond length, solvatation conditions...). Moreover, equation (12) leads to:

$$
-\operatorname{Ln}\left(\frac{1}{\Phi_{\infty}}-1\right)=-\operatorname{Ln}\left(\frac{F(I)\left(k_{e}+k_{-e} k_{d Q}\right)}{k_{d Q}}\right)+\operatorname{Ln}\left(k_{e}\right)
$$

Figure 8 displays the $\left(-\operatorname{Ln}\left(\left(1 / \Phi_{\infty}\right)-1\right)\right.$ parameter as a function of the difference of standard potentials between the exogenous quinone $\left(E_{Q}\right)$ and electron acceptor $Q_{A^{-}}\left(E_{Q A}\right)$ for four quinones. Briefly, all the data treatment (extracted values of $\Phi_{\infty}$ at $\mathrm{I}^{\circ}=340 \mu \mathrm{E} \cdot \mathrm{m}^{-2} \cdot \mathrm{s}^{-1}$ ) described above was performed for four quinones (NBQ, PPBQ, 2,6-
DCBQ and 2,5-DCBQ) and the standard potentials were extracted from previous works $(+0.042 ;+0.055 ;+0.004 ;-0.330 \vee$ vs SCE (Saturated Calomel Electrode) for the exogenous quinones respectively and $-0.450 \mathrm{~V}$ vs SCE for $\left.\mathrm{Q}_{A^{-}}^{-}\right){ }^{24,37}$ Interestingly, Figure 8 suggests a linear relationship instead of the expected parabolic curve. In that case, the quadratic term in equation (13) would be much lower than $0.5 \Delta_{\mathrm{r}} \mathrm{G}^{\circ} / \mathrm{RT}$ thus meaning the reorganization energy would be much higher than the driving forces investigated here. While a deeper analysis with other quinones involved in the mechanism considered in this work should be achieved to confirm this trend, such a behavior could be explained if assuming high reorganization energy. Indeed, due to altered interactions between quinones and proteins by the electron transfer, the resulting local protein structure reorganization in a confined environment should be more energy consuming than a usual solvatation sphere.

Consequently, our results support the mechanism suggested in Figure 5 (complementary validations are reported in Supporting Information, see Figures S2 and S4). It is of note that it does not fully exclude alternative mechanisms (see below). Moreover, the $\Phi_{\infty}$ values seem to be controlled by an electron transfer rate law, meaning that the $Q^{-} Q_{A}$ dissociation should be much faster than the electron transfer step.

Beyond the fact that our mechanism is validated by the experimental results, only considering one accepted electron by exogenous quinones needs to be discussed because the resulting semiquinone $Q^{-}$should not leave easily the $Q_{B}$ pocket. Therefore, a second electron should be accumulated leading to a final quinol species. Owing to the high affinity of quinones for the $Q_{B}$ pocket, ${ }^{31}$ an alternative mechanism with two successive electron transfer steps can be proposed similar to the plastoquinone reduction. All the corresponding equations are detailed in the Supporting Information. Indeed, despite much more complicated equations, such a bielectronic extraction mechanism also allows one to describe the effects of experimental conditions $\left(I^{\circ}, C_{Q}\right)$ on the quantities $\left(\Phi ; \Phi_{\infty} ; \Phi_{0} ; \rho_{0}\right)$ related to the extraction. On the one hand, it means that the intrinsic properties resulting from a two electrons mechanism cannot be detected in the range of experimental conditions and of sensitivity we considered in the present work. On the other hand, it especially means that applying a simple monoelectronic extraction to our results is adequate to build zone diagrams able to predict the most appropriate conditions and to give access to the zones in which the rate limiting step depends on quinone concentration (quinone binding into $Q_{B}$ pocket) or not.

\section{Zone diagram for deeper analysis of the extraction mechanism}

Predicting the effect of quinone concentration and light intensity on the photosynthetic electron extraction requires understanding the consequences of the model described here and more particularly the different steps that limit the whole process.

Thus, following the different rate constants in the mechanism (endogenous flow, electron transfer...) or the different experimental parameters (quinone concentration, incident light flow), the open centers ratio will not be controlled by the same flow (endogenous vs exogenous). Moreover, the rate determining step of exogenous flow may also differ (electron transfer vs quinone 
insertion). This is why we first sought to build a general zone diagram to summarize prominent flows and rate limiting steps as a function of the different rate constants and experimental parameters. To do so, one has to consider the expression of the open centers ratio in equation (8). If considering that the presence of exogenous quinones induces a corresponding electron flow, the ratio between the exogenous (due to $\mathrm{C}_{\mathrm{Q}}$ ) flux $\left(\mathrm{J}_{\mathrm{exo}}\right)$ and endogenous electron (due to $k_{\text {endo }}$ ) flux ( $\mathrm{J}_{\text {exo }}$ ) is defined as $\alpha$ according to (see details in Supporting Information):

$$
\alpha=\frac{J_{\text {exo }}}{J_{\text {endo }}} \quad C_{Q} \frac{k_{Q} k_{d Q} k_{e}}{k_{\text {endo }}\left(k_{-Q} k_{-e}+k_{-Q} k_{d Q}+k_{d Q} k_{e}\right)}
$$

Therefore, the adimensional parameter $\alpha$ notably depends on the quinone concentration $\mathrm{C}_{Q}$ whose value will directly play a significant role on the prevalent flux. For instance, if $\alpha>1$, the exogenous flux will predominate.

Moreover, if considering equation (15), equation (8) becomes:

$$
\Phi=\frac{k_{\text {endo }}(1+\alpha)}{\left(k_{\text {endo }}+F(I)\right)+\alpha k_{\text {endo }}\left(\frac{F(I)\left(k_{e}+k_{-e}\right.}{k_{d Q} k_{e}}+1\right)}
$$

Furthermore, as displayed in Figure $\mathbf{5 B}$, the available quinone concentration $\left(C_{Q}\right)$ will only modify the quinone insertion rate. As a consequence, the exogenous flux can be rate-determined either by the exogenous quinone $Q$ arrival within the $Q_{B}$ pocket or the subsequent electron transfer between $Q$ and $Q_{A}$. The prevalence of each is thus related to the comparison between the quinone concentration dependent and non dependent terms of the denominator in equation (8). A second adimensional parameter $\beta$ can be defined:

$$
\beta=\frac{k_{\text {endo }}+F(I}{k_{\text {endo }}\left(\frac{F(I)\left(k_{e}+k_{-e} k_{d Q}\right)}{k_{d Q} k_{e}}+1\right)}
$$

$\beta$ corresponds to a specific $\alpha$ value for which quinone insertion and electron transfer rates are equal. The electron transfer rate will be much higher than the insertion if $\alpha<\beta$ thus leading to the quinone insertion as the rate determining step. Equation (16) finally becomes:

$$
\Phi=\frac{k_{\text {endo }}(1+\alpha) \beta}{\left(k_{\text {endo }}+F(I)\right)(\alpha+\beta)}=\Phi_{0} \frac{(1+\alpha) \beta}{\alpha+\beta}
$$

The corresponding zone diagram is depicted in Figure 9. Such a diagram illustrates how the open centers ratio depends on the quinone concentration in a specific manner related to the prevalence of electron fluxes and kinetics. The yellow line splits the diagrams into two zones related to $\beta$ values, i.e. a normal region for $\beta>1$ (that leads to a $\Phi$ increasing function) and an inverted region for $\beta<1$ (that leads to a $\Phi$ decreasing). Comparing $\alpha$ value to 1 and $\alpha$ to $\beta$ allows one to define 9 main zones corresponding to a specific dependence of $\Phi$ towards $C_{0}$, as listed in Table 2.
Particularly, equation (17) shows that the transition between inverted and normal regions is based on the $k_{\text {endo }}\left(k_{e}+k_{-e}+\right.$ $\left.k_{d a}\right) /\left(k_{d Q} k_{e}\right)$ value. If $k_{\text {endo }}<\left(k_{d q} k_{e}\right) /\left(k_{e}+k_{-e}+k_{d a}\right)$ (i.e. $\left.\beta>1\right)$, the quinone addition and insertion leads to a state $\left(\mathrm{QQ}_{A_{A}}{ }^{-}\right)$that releases its charge faster than $\left(Q_{A}^{-}\right)$by endogenous flow. The open centers ratio is thus expected to increase with the added quinone concentration. Conversely, if $k_{\text {endo }}>\left(k_{d a} k_{e}\right) /\left(k_{e}+k_{-e}+k_{d a}\right)$ (i.e. $\beta<$ $1)$, the back formation of $Q_{A}$ from $Q_{A}{ }^{-}$will be faster than the charge release of $\left(\mathrm{QQ}_{A}^{-}\right)$accumulated when quinone concentration increases.

The open centers ratio is thus expected to decrease with the added quinone concentration. Such trends are readily observed in three inverted zones $(1,8,9)$ and three normal zones $(4,6,7)$. Finally, two peculiar zones ( 2 and 3 ) are independent of the quinone concentration. Indeed, if the endogenous flow prevails with a limiting quinone transport (zone 2), the quinone insertion is prevented by the back formation of $Q_{A}$. Therefore, no significant extraction by the exogenous quinone can occur and the resulting open centers ratio will be close to its value in absence of quinone. Conversely, if the exogenous flux prevails with a limiting electron transfer step (zone 3 ), the quinone insertion is a very fast step. On the one hand, the extraction rate does not depend on $\mathrm{C}_{Q}$ and on the other hand, the open centers ratio will reach its maximum value $\left(\Phi_{\infty}\right)$ under these irradiation conditions.

It is worth mentioning that the inverted region corresponds to a counter-intuitive behavior because increasing the exogenous quinone concentration decreases the open centers ratio. In other words, inverted region corresponds to conditions for which adding an oxidant leads to a more reduced system. Hence, another way to validate the suggested mechanism is to experimentally demonstrate that inverted region exists. The established zone diagram shows it can be achieved by considering another system (quinone/algae) whose electron transfer kinetics (step generating $\left(Q^{-} Q_{A}\right)$ from $\left.\left(Q^{-}{ }_{A}\right)\right)$ is rather low if compared to endogenous flow (direct back generation of $Q_{A}$ starting from $Q_{A}^{-}$). Experiments were thus carried out with 2,6-DCBQ with wild-type algae for which the endogenous flow is expected to be larger (the photosynthetic chain is complete, thus the endogenous flow rate constant $k_{e}$ is higher than the mutant one). Nevertheless, increasing the quinone concentration still leads to the open centers ratio increase (see Figure S3 and Table T1 in Supporting Information), thus meaning that experimental conditions still correspond to the normal region of the diagram because the endogenous flow, although much stronger than in mutant case, remains slower than electron transfer to 2,6-DCBO

As a consequence, other experiments were still performed with wild-type algae but in presence of an electron PSII acceptor, naphtoquinone (NQ), that was previously demonstrated as limited by a low $\Phi_{\infty}$ value. Such a result is consistent with its low midpotentiel value, ${ }^{24}$ that suggests a slow electron transfer after binding within the $Q_{B}$ pocket. Hence, applying the experiments and data treatment with population of $b_{6} f$ mutant or wild type algae gives the $\Phi=f\left(C_{Q}\right)$ depicted in Figure $\mathbf{1 0}$ and corresponds to the expected poor reductive capability of $\mathrm{NQ}$ In the mutant case, the open centers ratio is still an increasing function because, although the electron transfer is also slow, the endogenous flow is slower. However, in the wild type case, the electron transfer step is not 
only slow but also takes place in presence of an initial significant endogenous flow. Therefore exogenous quinone addition will shortcircuit the endogenous flow and lead to an accumulation of closed reaction centers $\left(\mathrm{QQ}_{\mathrm{A}}{ }^{-}\right)$thus resulting in a decrease of $\Phi$ as a function of quinone concentration. This is why the inverted region of the diagram was thus reached for such experimental conditions, thus strengthening the extraction mechanism investigated here and its use for predicting the effects of the added quinone concentration and the light intensity.

\section{Building of a zone diagram for deciphering the effects of quinone concentration and light intensity}

In order to predict the effect of quinone concentration and light intensity on the photosynthetic electron extraction, another zone diagram can be built owing to the experimentally extracted values of $\Phi_{0}, \rho_{0}$ and $\Phi_{\infty}$ for the 2,6-DCBQ and the mutant without $b_{6} f$. Hence, the $\Phi$ values can be predicted by the mean of equation (2) for the light intensities investigated in the present work. Such results can then be used to build a new zone diagram that will display the effect of quinone concentration and light intensity on the open centers ratio value (see Figure $\mathbf{1 1}$ for the mutant case. A similar diagram can be built for the wild-type case, see Figure $\mathbf{S 5}$ in Supporting Information). First of all, the inverted regions described in Figure 9 (corresponding to zones 1, 8, 9 and partially 2, 3, 5) cannot be observed. Indeed, experimental data showed that the open centers ratio globally increased with the quinone concentration. It means that $\beta>1$ in the $2,6-\mathrm{DCBQ}$ case. This prevents direct observation of inverted zones and suggests that that the electron transfer between the exogenous quinone and $Q_{A}^{-}$ is faster than the endogenous flow. It is worth mentioning that observation of inverted zones is quinone and algae dependent, although quinone concentration and light intensity independent. Indeed, the above experiments involving NQ with wild-type algae have shown a $\Phi$ decrease while increasing $C_{Q}$ thus featuring an inverted behavior with $\beta<1$.

Hence, among all the zones being or crossing the inverted region (see Figure 9), only zones 2, 3, 5 are still observed. Finally, as mentioned above, all the regular zones are observed excepting zone 4 (where exogenous flow predominates and mass transport is rate-determining). Absence of zone 4 is consistent with the fact that when exogenous flux controls the open centers ratio, the electron transfer kinetics limitation cannot be neglected. Indeed, by assuming that a term can be neglected in a sum if less than $10 \%$ of the other terms, such a zone corresponds to $\beta>100$ because exogenous flow is assumed to predominate $(\alpha>10)$ with a mass transport limitation $(\beta>10 \alpha)$. In other words, it would need that $\mathrm{QQ}_{A^{-}}$release its charge at least 100 times faster than $\mathrm{Q}_{A^{-}}$with endogenous flow. So the higher the difference between $\beta$ and 100 , the bigger zone 4 area. According to equation (9), (11) and (17), $\beta$ can be calculated as:

$$
\beta=\frac{\frac{1}{\Phi_{0}}-1}{\frac{1}{\Phi_{\infty}}-1}
$$

By using the slopes previously extracted, a $\beta$ value equal to 100 is obtained. These peculiar conditions just being below the threshold of zone 4 existence, zone 4 is therefore not observed. Beyond the mapping of the open centers ratio, such a zone diagram can help to identify specific experimental conditions for photosynthetic electron extraction.

More particularly, such a diagram allows us to predict the effects of exogenous quinone concentration at a given incident light. Very low quinone concentrations lead to experimental conditions corresponding to zone 2 . This case $\left(\Phi=\Phi_{0}\right)$ is obviously not suitable because, according to the biological redox state sensitivity, no significant extraction will occur. Conversely, working with a moderate exogenous quinone concentration will lead to experimental conditions defining zone $6\left(\Phi_{0}=\Phi_{0}+\rho_{0} C_{Q}\right)$ at high incident lights. It thus allows one to extract the photosynthetic electrons without altering the endogenous flux. However, the open centers ratio will not reach its maximum value $\left(\Phi_{\infty}\right)$, thus does not describe the optimal conditions to avoid photoinhibition. The best extraction can be obtained by working at high quinone concentrations thus leading to experimental conditions corresponding to zone $3\left(\Phi=\Phi_{\infty}\right)$. It allows one to perform electron extraction with the maximum efficiency at a given light intensity. This is why, at a given incident light intensity, working at the frontier between zones 3 and 7 should provide interesting conditions since they would lead to the maximum $\Phi$ value with a quinone concentration kept as low as possible. The harvesting should thus be strongest while potentially reducing damages resulting from photoinhibition. Nevertheless, because of the competition between endogenous and exogenous flows, increasing the electron extraction would drastically reduce the endogenous flow. It will therefore limit the NADPH formation which is also instrumental for algae viability.

Therefore, it is difficult to define the best zone for photosynthetic electron extraction. Indeed, one of the key points is the competition between endogenous and exogenous flows that are controlled by the light intensity and the exogenous quinone concentration. The choice should depend of the purpose of the investigation and the experimental conditions. Indeed, working without any energy source as an organic matter in the medium and maintaining algae alive for quite a long time should lead one to maintain a quite strong endogenous flow (and NADPH production). Zone 6 should thus be needed by working with relatively low quinone concentrations and moderate incident lights. It would be optimal for $\mathrm{CO}_{2}$ consumption although the incident light flow should be carefully controlled because of possible photoinhibition during this extraction process. Moreover, a $b_{6} f$ lacking mutant would not be necessarily the most appropriate system for such an investigation, due to its very low endogenous flow. Conversely, working to harvest photosynthetic electrons and produce maximimum photocurrents values while also minimizing photoinhibition would require being at the frontier between zones 3 and 7 . However, the system will be not totally efficient concerning the $\mathrm{CO}_{2}$ reduction. Additionally, an organic matter source in the medium will be needed to preserve the algae life time. 


\section{Experimental}

\section{Cell culture and preparation}

We used a wild type strain of Chlamydomonas reinhardtii, derived from $137 \mathrm{c}$ and a $\Delta$ pet $A$ mutant ${ }^{38}$ that lacks cytochrome $b_{6} f$ because of a deletion of the chloroplast gene encoding cytochrome $f$. Cytochrome $b_{6} f$ is a quinol:plastocyanin oxidoreductase in the absence of which the plastoquinol generated by light-induced turnovers of Photosystem II cannot be reoxidized, leading to the rapid arrest of light-driven electron flow. We characterized the respective ability of several distinct quinones to rescue a photoinduced electron flow in the mutant, using fluorescence to assess the Photosystem II photochemical rate. ${ }^{25}$ Briefly, cells were grown in Tris Acetate Phosphate medium (TAP) containing Tris base (20 mmol.L-1), $\mathrm{NH}_{4} \mathrm{Cl}\left(7 \mathrm{mmol} . \mathrm{L}^{-1}\right), \mathrm{MgSO}_{4}\left(0.83 \mathrm{mmol} . \mathrm{L}^{-1}\right), \mathrm{CaCl}_{2}$ (0.45 mmol.L-1), $\mathrm{K}_{2} \mathrm{HPO}_{4}\left(1.65 \mathrm{mmol}^{-L^{-1}}\right), \mathrm{KH}_{2} \mathrm{PO}_{4}\left(1.05 \mathrm{mmol} . \mathrm{L}^{-1}\right)$ at $25^{\circ} \mathrm{C}$ under moderate illumination $\left(50 \mu \mathrm{E} . \mathrm{m}^{-2} . \mathrm{s}^{-1}\right)$ then centrifugated at $4000 \mathrm{rpm}$ and then re-suspended into minimum medium $\left(\begin{array}{lll}\mathrm{K}_{2} \mathrm{HPO}_{4} & \left.\text { (4.1 mmol. } \mathrm{L}^{-1}\right), \quad \mathrm{KH}_{2} \mathrm{PO}_{4} & \left(2.1 \mathrm{mmol} . \mathrm{L}^{-1}\right.\end{array}\right), \mathrm{CaCl}_{2} \quad(0.45$ mmol.L-1 $), \mathrm{NH}_{4} \mathrm{Cl}\left(7.5 \mathrm{mmol} . \mathrm{L}^{-1}\right), \mathrm{MgSO}_{4}\left(0.85 \mathrm{mmol}^{-\mathrm{L}^{-1}}\right)$ to a concentration of $10^{7}$ cells. $\mathrm{mL}^{-1}$.

\section{Chemical materials and solutions preparation}

All chemicals were purchased from Sigma Aldrich and used without any further purification. Quinones were dissolved in absolute ethanol in order to make stock solutions (typically $10 \mathrm{mmol} . \mathrm{L}^{-1}$ ). Appropriate small volumes of such quinone solutions were directly added into a cuvette containing the algae suspension $(\mathrm{V}=2 \mathrm{~mL})$ to reach the final expected concentration. The cuvette was then stirred manually before experiments.

\section{Fluorescence Measurements and Data acquisition}

Fluorescence intensities were measured using a JTS spectrophotometer (Biologic) in which fluorescence was sampled with short flashes (4 $\mu \mathrm{s}$ duration) with negligible actinic (photobiological) effect. The detecting light for sampling fluorescence was provided by white LED's and the wavelength (440 $\mathrm{nm}$ ) defined by a combination of 3 mm BG39 and BG3 Schott filters. Open centers ratio was calculated by the mean of the saturation pulse method (see text). ${ }^{25}$, 39 The actinic (excitation) light was provided by a red LED $(640 \mathrm{~nm})$. This was used to promote excitation of PSII (continuous illumination with a steady state fluorescence $F_{\text {stat, }}$, see light intensities in text) and then to induce a full reduction of the electron acceptors by the mean of a saturating pulse $\left(5000 \mu \mathrm{E} . \mathrm{m}^{-2} . \mathrm{s}^{-1} ; 250 \mathrm{~ms}\right.$ duration; fluorescence value $F_{\max }$ was measured $100 \mu$ s after the pulse was turned off; see Supporting Information). ${ }^{40,41}$

\section{Simulations and Data treatment}

Modeling and data treatment were performed using OriginPro 8.1 software (OriginLab company, Northampton, MA 01060 USA) and Mathematica 9.0 student edition software (Wolfram Research Inc, Champaign Illinois).

\section{Conclusions}

In this work we used fluorescence measurements to extract the open centers ratio within a population of photosynthetic algae. Furthermore, we consider it as a proxy for investigating the extraction of photosynthetic electrons by the mean of an exogenous quinone, 2,6-DCBQ. A mechanism was suggested and was globally found consistent with the experimentally extracted parameters. Zone diagrams were constructed to identify the most appropriate experimental conditions (quinone concentration, light intensity) depending on the desired usage of the photosynthetic electron harvesting. As a consequence, it stresses the choice to preserve endogenous flow or to minimize photoinhibition and extract high photocurrent.

\section{Acknowledgements}

This work has been supported in part by CNRS (UMR 8640, UMR7141), Ecole Normale Supérieure, French Ministry of Research, Université Pierre \& Marie Curie Paris 06, the "Fondation Pierre-Gilles de Gennes pour la Recherche" FPGG0049 and the "Initiative d'Excellence" program from the French state (Grant "DYNAMO", ANR-11-LABX-0011-01). Dr. Benjamin Bailleul is gratefully acknowledged for fruitful discussions.

\section{Notes and references}

1. R. E. Blankenship, D. M. Tiede, J. Barber, G. W. Brudvig, G. Fleming, M. Ghirardi, M. R. Gunner, W. Junge, D. M. Kramer, A. Melis, T. A. Moore, C. C. Moser, D. G. Nocera, A. J. Nozik, D. R. Ort, W. W. Parson, R. C. Prince and R. T. Sayre, Science, 2011, 332, 805-809.

2. T. Roach and A. Krieger-Liszkay, Curr. Protein Peptide Sci., 2014, 15, 351-362.

3. M. Rasmussen and S. D. Minteer, Electrochim. Acta, 2014, 126, 68-73.

4. M. Rasmussen and S. D. Minteer, Phys. Chem. Chem. Phys., 2014, 16, 17327-17331.

5. H. Hamidi, K. Hasan, S. C. Emek, Y. Dilgin, H.-E. Akerlund, P.A. Albertsson, D. Leech and L. Gorton, ChemSuschem, 2015, 8, 990-993.

6. K. Hasan, Y. Dilgin, S. C. Emek, M. Tavahodi, H.-E. Akerlund, P.-A. Albertsson and L. Gorton, Chemelectrochem, 2014, 1, 131-139.

7. J. O. Calkins, Y. Umasankar, H. O'Neill and R. P. Ramasamy, Energy Environ. Sci., 2013, 6, 1891-1900.

8. A. Badura, T. Kothe, W. Schuhmann and M. Roegner, Energy Environ. Sci., 2011, 4, 3263-3274.

9. R. Tel-Vered and I. Willner, Chemelectrochem, 2014, 1, 17781797.

10. T. Kothe, S. Poeller, F. Zhao, P. Fortgang, M. Roegner, W. Schuhmann and N. Plumere, Chem. Eur. J., 2014, 20, 1102911034. 
11. F. Zhao, K. Sliozberg, M. Roegner, N. Plumere and W. Schuhmann, J. Electrochem. Soc., 2014, 161, H3035-H3041.

12. K. Hasan, H. B. Yildiz, E. Sperling, P. O. Conghaile, M. A. Packer, D. Leech, C. Hagerhall and L. Gorton, Phys. Chem. Chem. Phys., 2014, 16, 24676-24680.

13. P. Bombelli, R. W. Bradley, A. M. Scott, A. J. Philips, A. J. McCormick, S. M. Cruz, A. Anderson, K. Yunus, D. S. Bendall, P. J. Cameron, J. M. Davies, A. G. Smith, C. J. Howe and A. C. Fisher, Energy Environ. Sci., 2011, 4, 4690-4698.

14. P. Bombelli, T. Mueller, T. W. Herling, C. J. Howe and T. P. J. Knowles, Adv. Energy Mat., 2015, 5.

15. R. W. Bradley, P. Bombelli, D. J. Lea-Smith and C. J. Howe, Phys. Chem. Chem. Phys., 2013, 15, 13611-13618.

16. J. M. Pisciotta, Y. Zou and I. V. Baskakov, Plos One, 2010, 5.

17. A. J. McCormick, P. Bombelli, A. M. Scott, A. J. Philips, A. G. Smith, A. C. Fisher and C. J. Howe, Energy Environ. Sci., 2011, 4, 4699-4709.

18. J. P. Giraldo, M. P. Landry, S. M. Faltermeier, T. P. McNicholas, N. M. Iverson, A. A. Boghossian, N. F. Reuel, A. J. Hilmer, F. Sen, J. A. Brew and M. S. Strano, Nat. Mat., 2014, 13, 400-408.

19. E. Stavrinidou, R. Gabrielsson, E. Gomez, X. Crispin, O. Nilsson, D. T. Simon and M. Berggren, Sci. Adv., 2015, 1, e1501136-e1501136.

20. M. Kasuno, M. Torimura, Y. Tsukatani, D. Murakami, S. Hanada, T. Matsushita and H. Tao, J. Electroanal. Chem., 2009, 636, 101-106.

21. Z. Chen, Y. Lyu, K. Wang, X. Dong, M. Deng, C. Bai, Y. Xu, W. Zhang and Z. Liu, Int. J. Hydrogen Energy, 2013, 38, 1304513049.

22. K. Hasan, K. V. R. Reddy, V. Essmann, K. Gorecki, P. O. Conghaile, W. Schuhmann, D. Leech, C. Hagerhall and L. Gorton, Electroanalysis, 2015, 27, 118-127.

23. K. Hasan, E. Cevik, E. Sperling, M. A. Packer, D. Leech and L. Gorton, Adv. Energy Mat., 2015, 5, 1501100.

24. G. Longatte, H.-Y. Fu, O. Buriez, E. Labbe, F.-A. Wollman, C. Amatore, F. Rappaport, M. Guille-Collignon and F. Lemaitre, Biophys. Chem., 2015, 205, 1-8.

25. K. Maxwell and G. N. Johnson, J. Exp. Bot., 2000, 51, 659-668.

26. B. Genty, J. M. Briantais and N. R. Baker, Biochim. Biophys. Acta, 1989, 990, 87-92.

27. K. A. Ahrling and S. Peterson, Biochemistry, 2003, 42, 76557662.

28. B. A. Diner and V. Petrouleas, Biochim. Biophys. Acta, 1987, 893, 138-148.

29. H. M. Gleiter, E. Haag, Y. Inoue and G. Renger, Photosynth. Res., 1993, 35, 41-53.

30. E. Haag, H. M. Gleiter and G. Renger, Photosynth. Res., 1992, 31, 113-126.

31. D. Joly and R. Carpentier, J. Photochem. Photobiol. B: Biol., 2007, 88, 43-50.

32. D. Shevela and J. Messinger, Biochim. Biophys. Acta Bioenergetics, 2012, 1817, 1208-1212.

33. J. L. Zimmermann and A. W. Rutherford, Biochim. Biophys. Acta, 1986, 851, 416-423.

34. S. Dudekula and M. Fragata, J. Photochem. Photobiol. B: Biol., 2006, 85, 177-183.
35. V. Petrouleas and B. A. Diner, Biochim. Biophys. Acta, 1987, 893, 126-137.

36. K. Satoh, M. Ohhashi, Y. Kashino and H. Koike, Plant Cell Physiol., 1995, 36, 597-605.

37. Govindjee and J. J. Eatonrye, Photosynth. Res., 1986, 10, 365379.

38. B. Rimbault, D. Esposito, D. Drapier, Y. Choquet, D. Stern and F. A. Wollman, Mol. Gen. Genet., 2000, 264, 486-491.

39. U. Schreiber, T. Endo, H. L. Mi and K. Asada, Plant Cell Physiol., 1995, 36, 873-882.

40. L. Houille-Vernes, F. Rappaport, F.-A. Wollman, J. Alric and X. Johnson, Proc. Natl. Acad. Sci. USA, 2011, 108, 20820-20825.

41. X. Johnson, G. Vandystadt, S. Bujaldon, F.-A. Wollman, R. Dubois, P. Roussel, J. Alric and D. Beal, Photosynth. Res., 2009, 102, 85-93. 


\section{FIGURES}

\section{Figure 1}

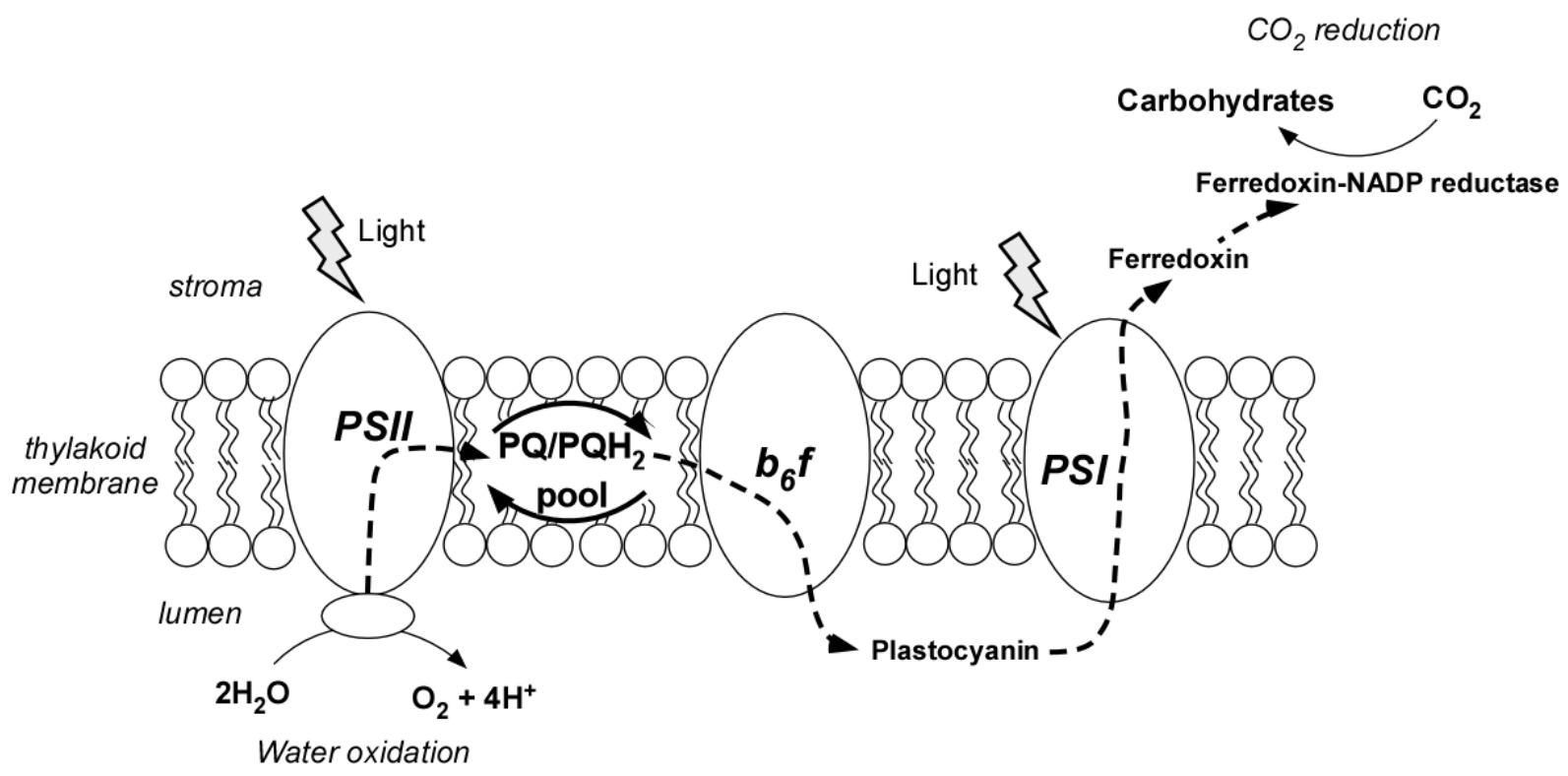


Figure 2

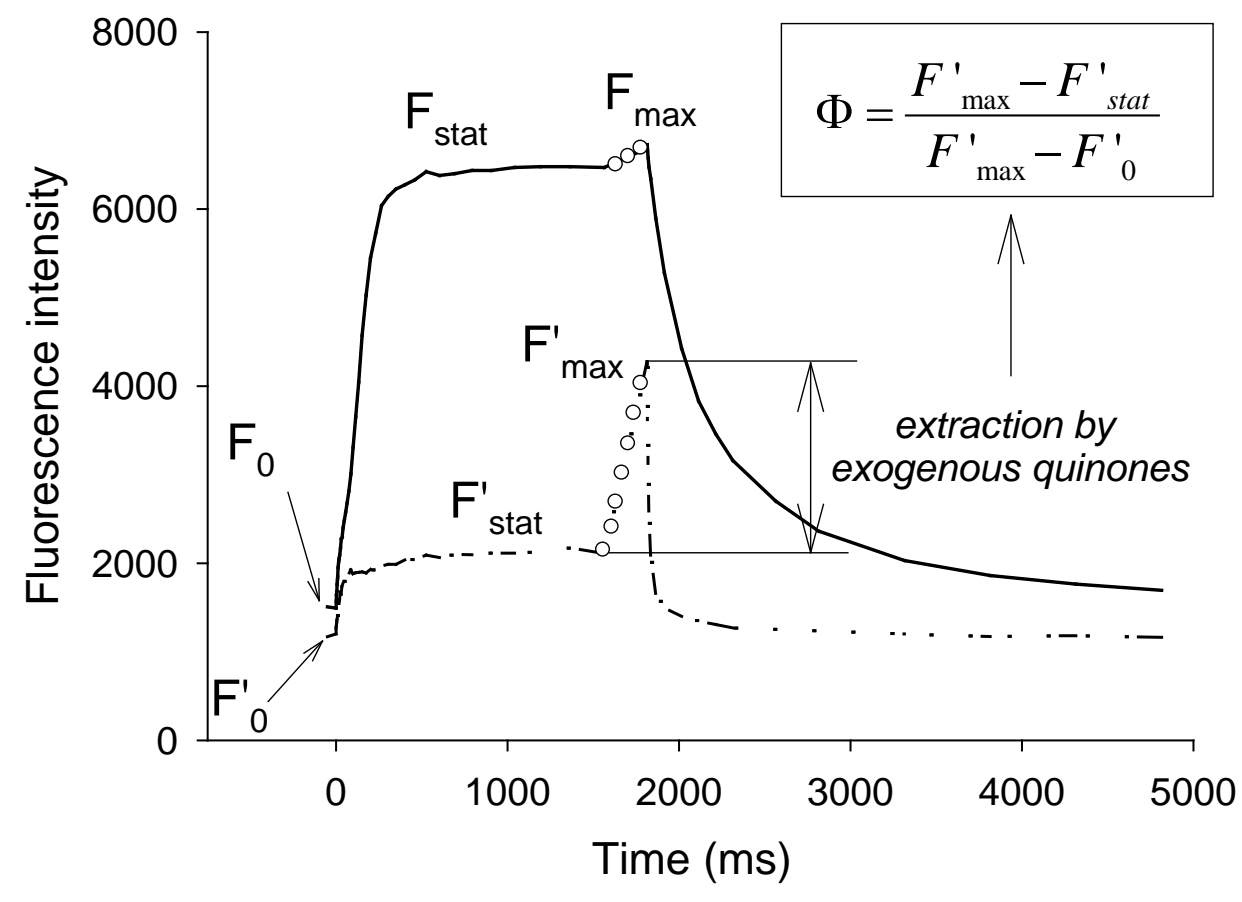


Figure 3

A)

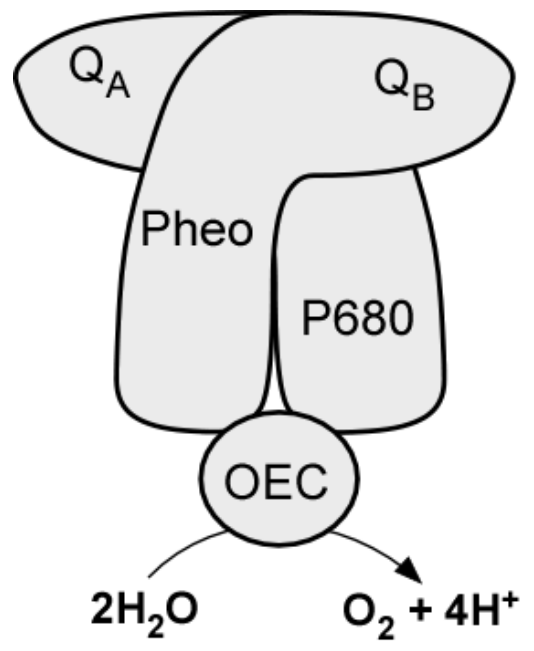

B)

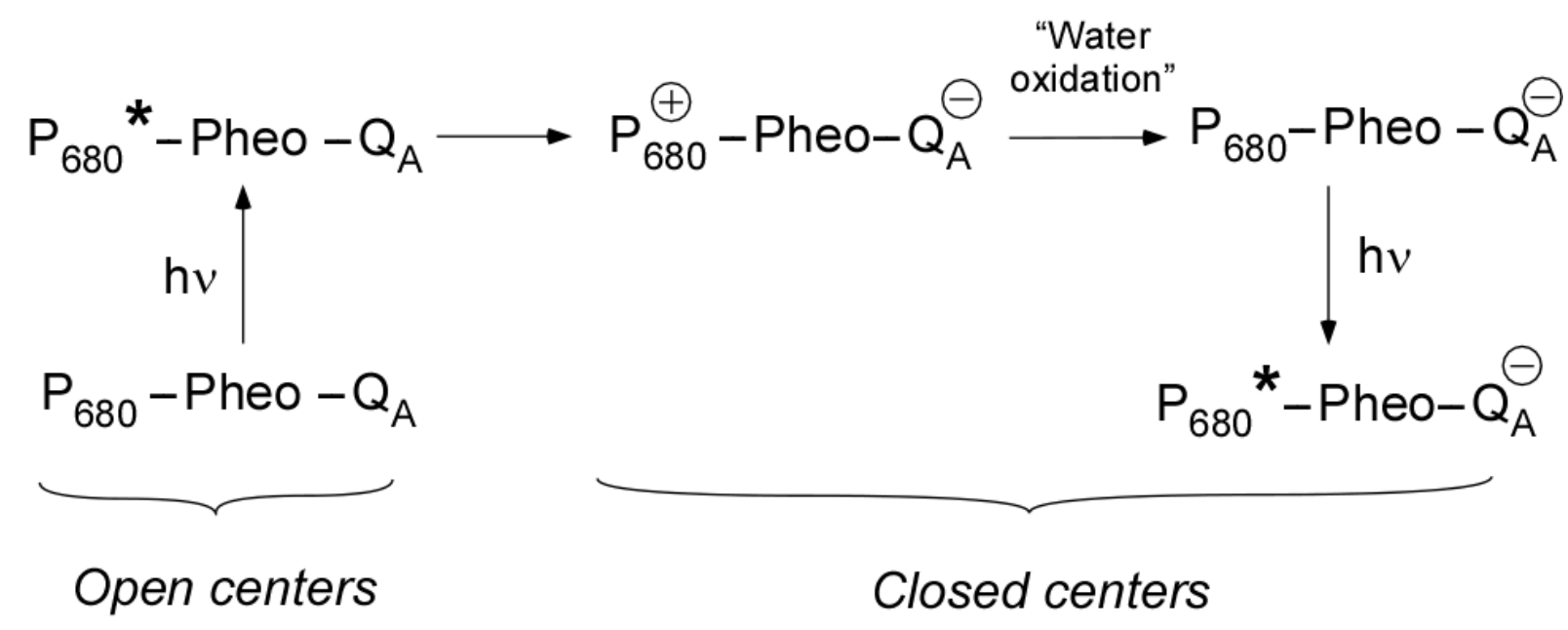


Figure 4

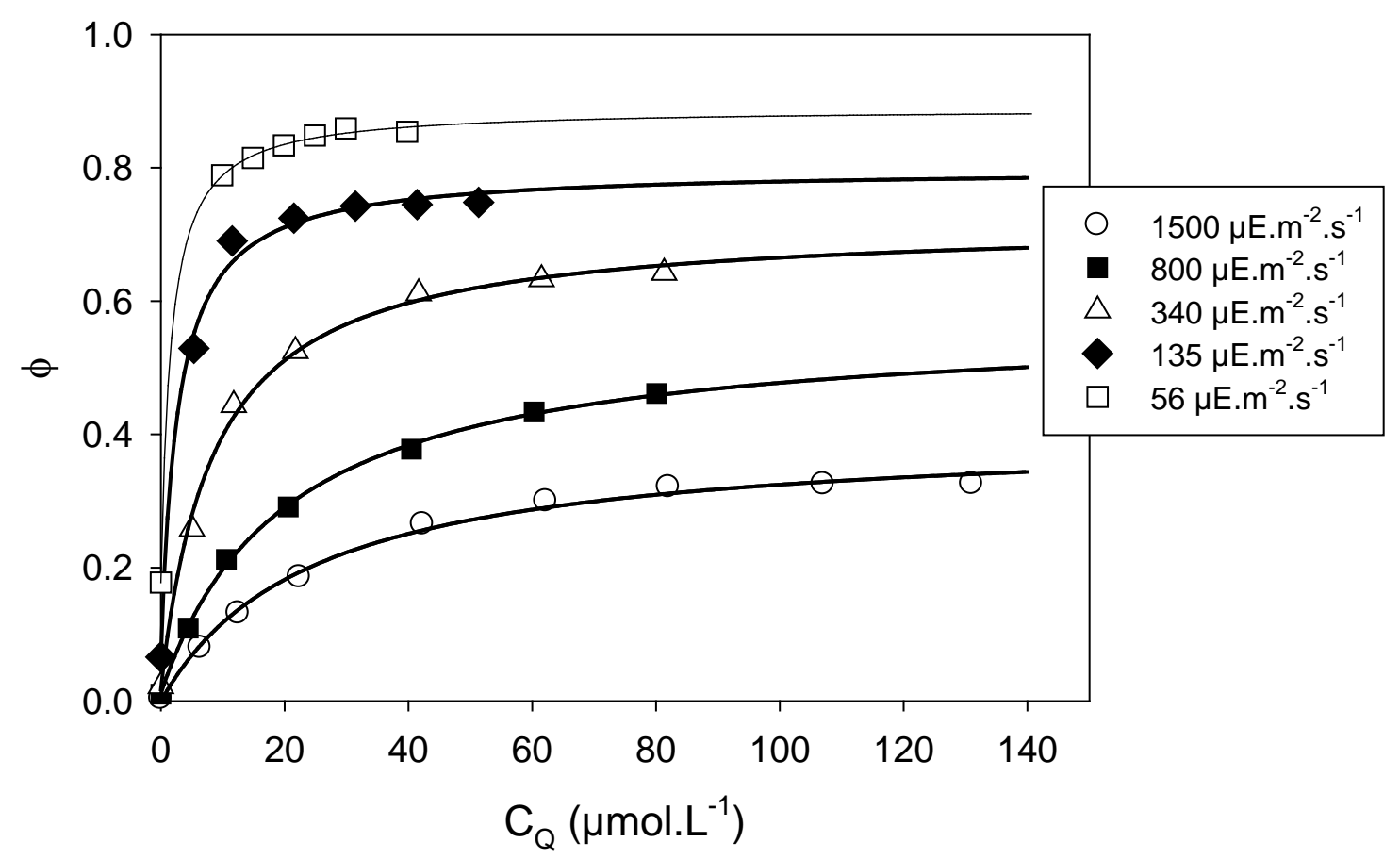


Figure 5

A)

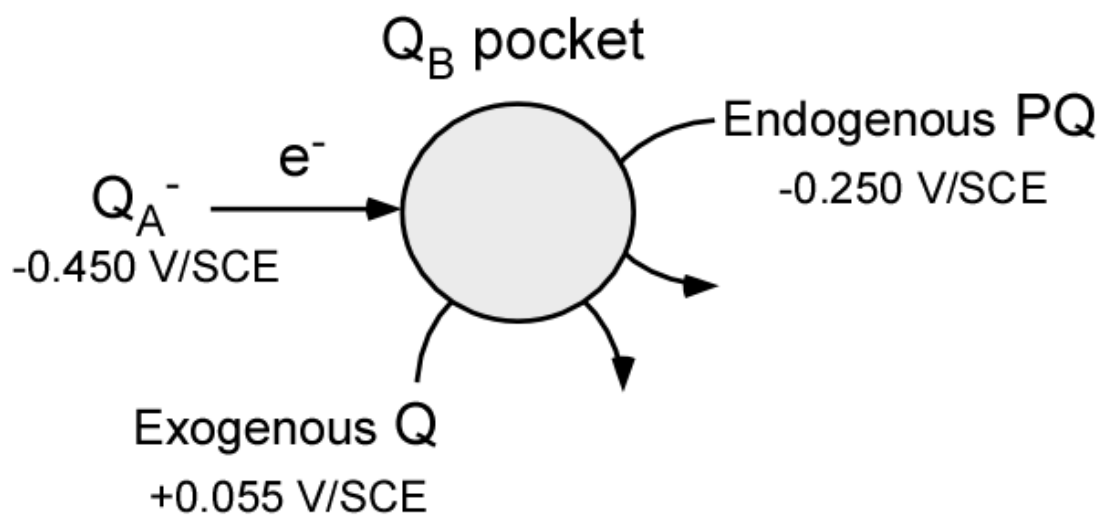

B)

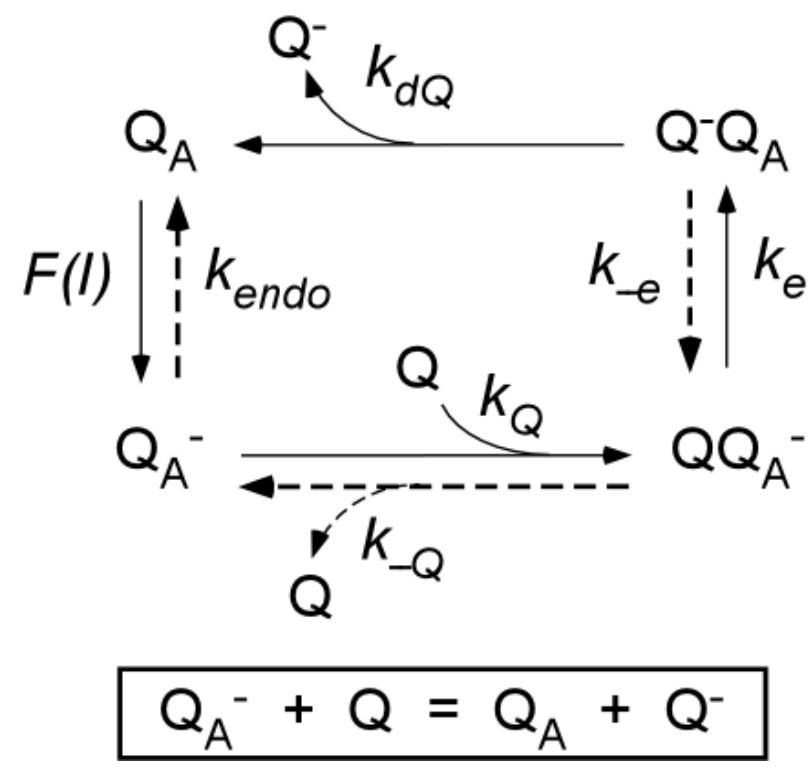


Figure 6

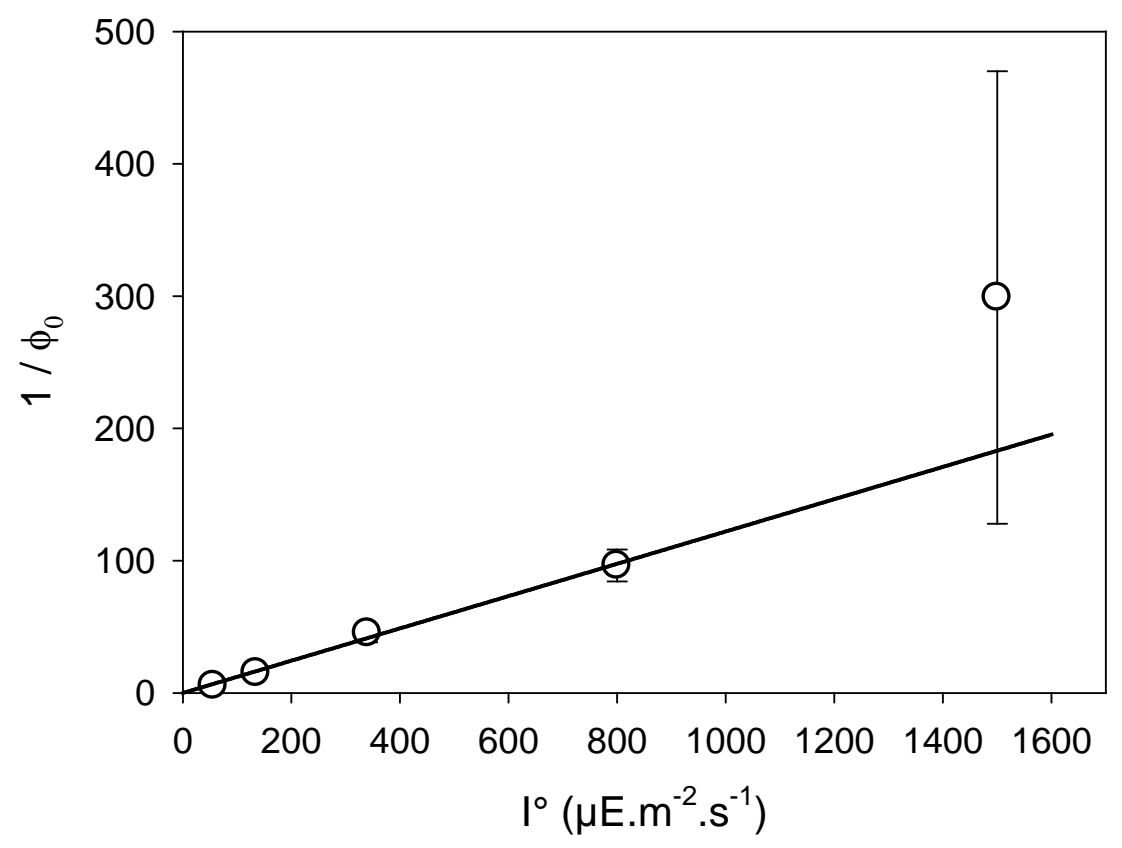


Figure 7

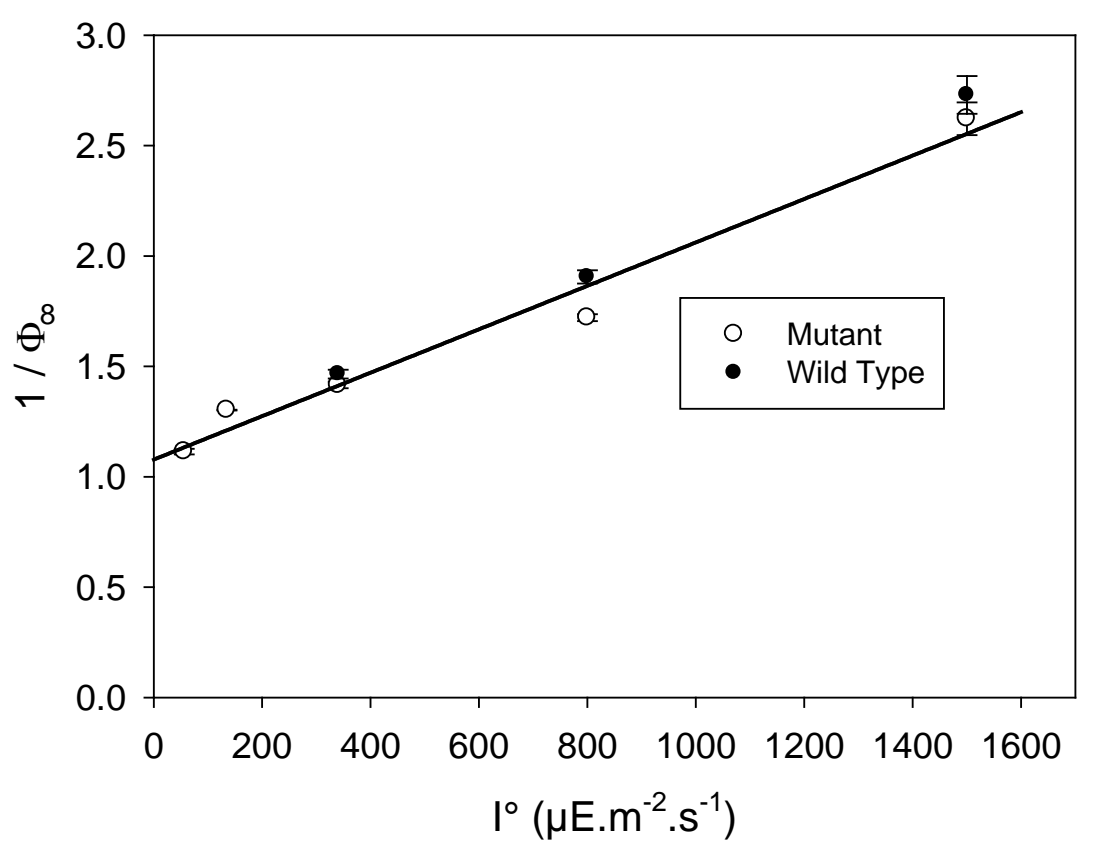


Figure 8

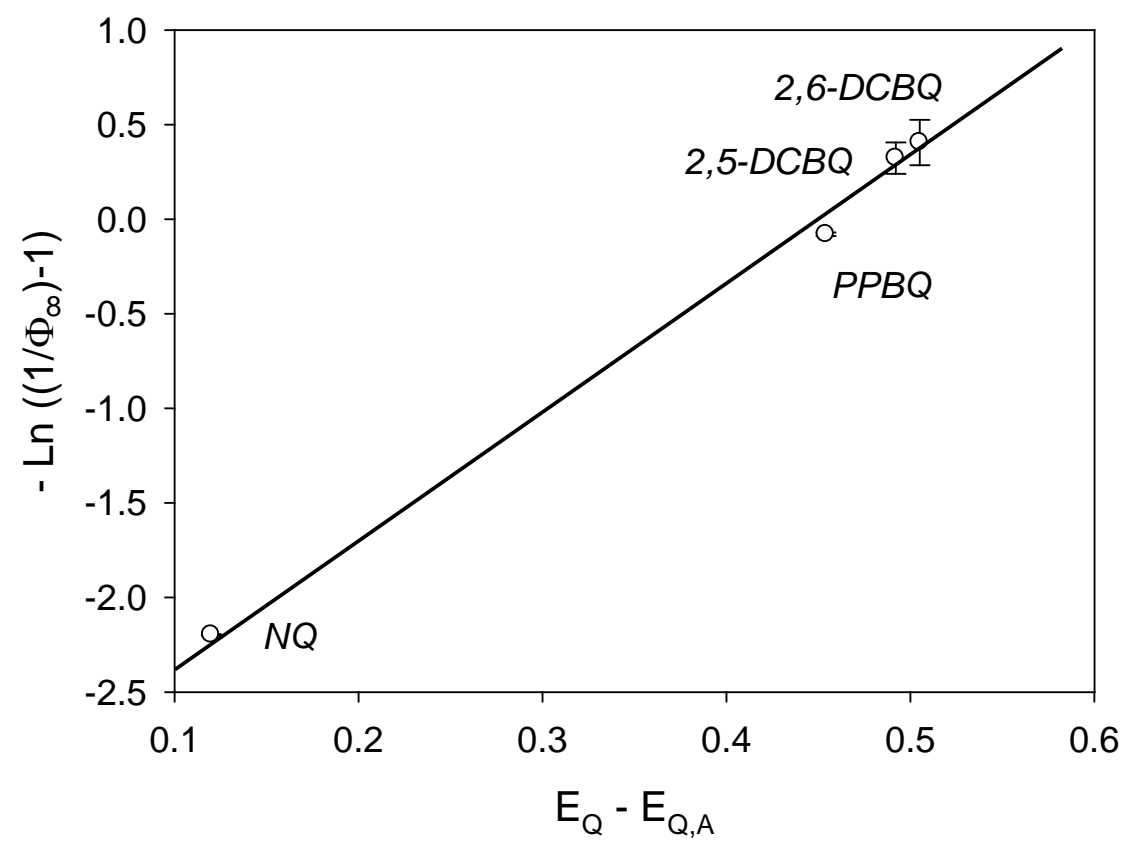


Figure 9

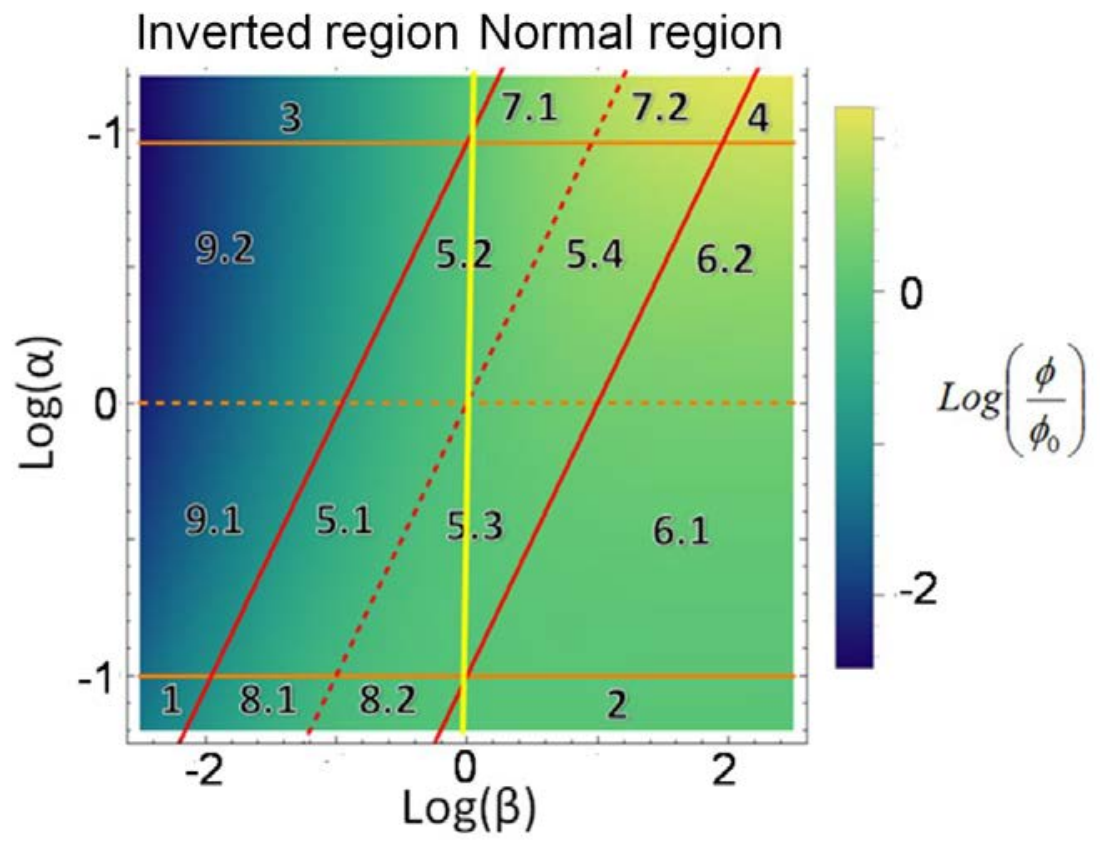


Figure 10

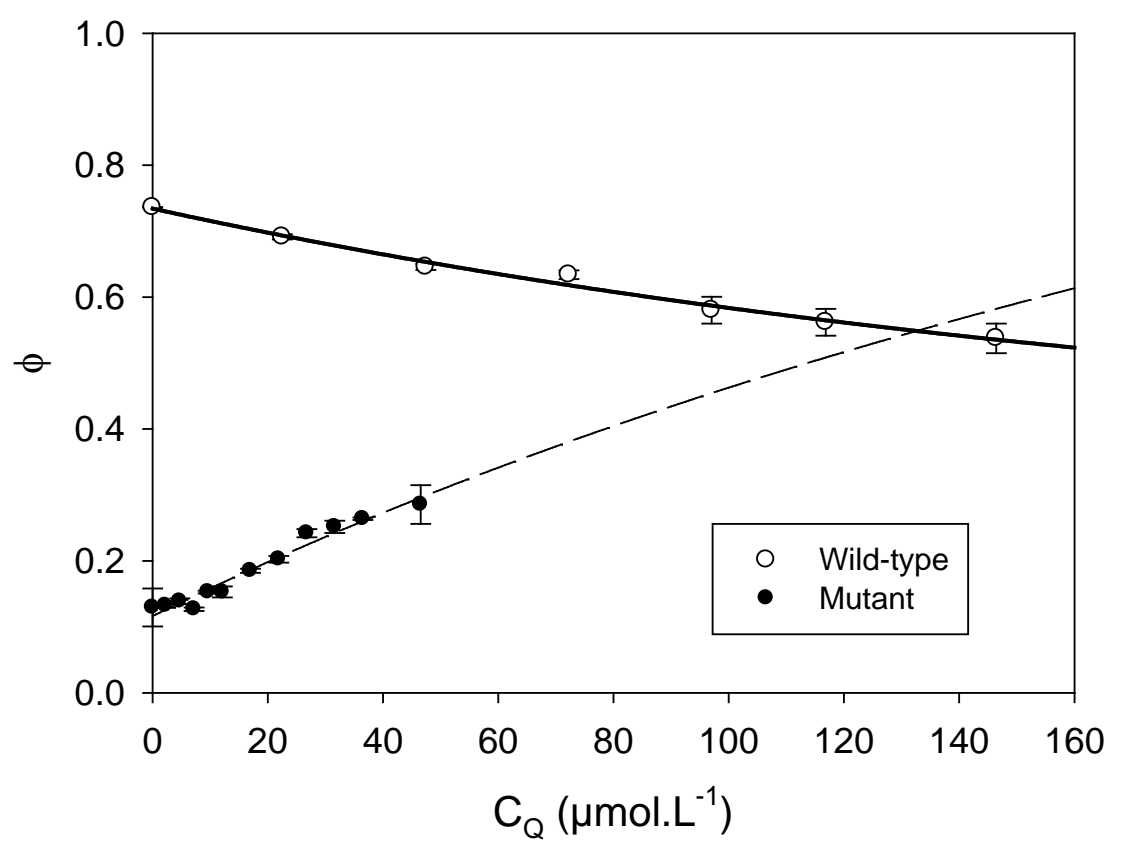


Figure 11

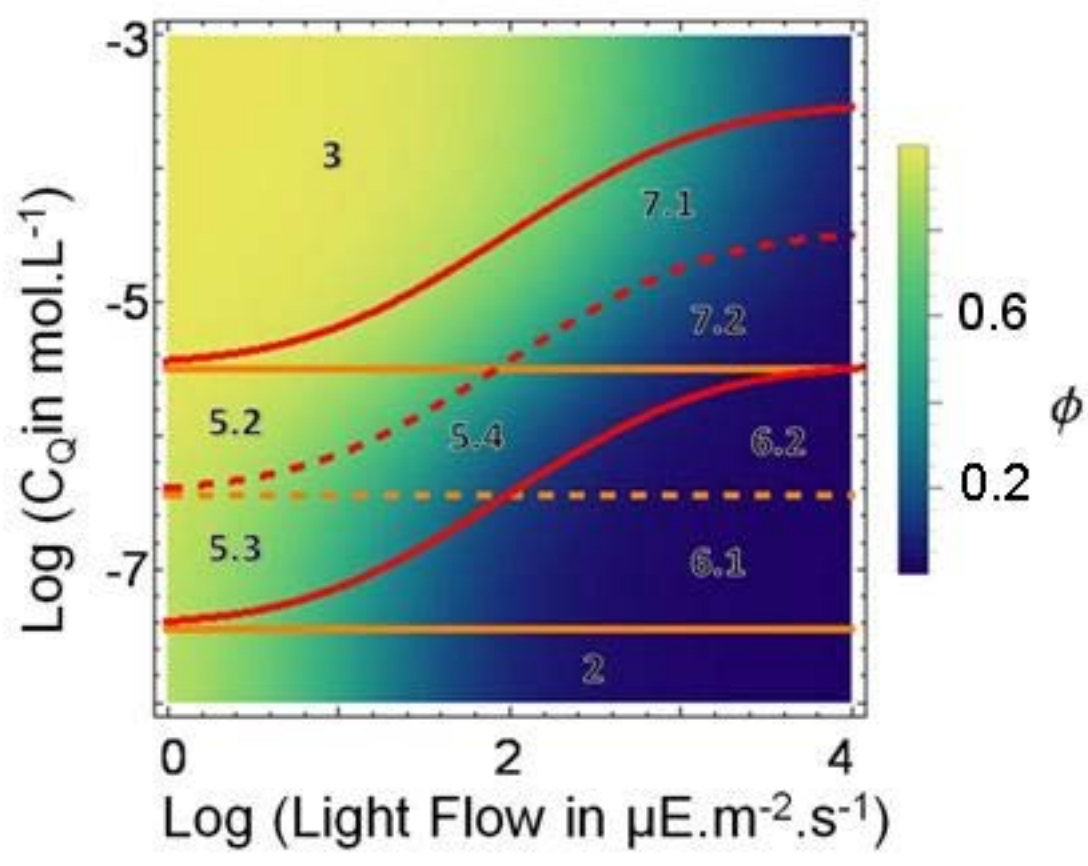




\section{TABLES}

\section{Table 1}

Effect of the light intensity $\mathrm{I}^{\circ}$ on the extracted values reflecting the electron extraction induced by the exogenous 2,6-DCBQ addition $\left(\Phi_{\infty}\right.$ and $\left.\rho_{0}\right)$ and the open centers ratio in absence of exogenous quinones $\left(\Phi_{0}\right)$ for mutant algae.

\begin{tabular}{|c|c|c|c|}
\hline $\mathrm{I}^{\circ}\left(\mu \mathrm{E} \cdot \mathrm{m}^{-2} \cdot \mathrm{s}^{-1}\right)$ & $\Phi_{\infty}$ & $\rho_{0}\left(\mu \mathrm{mol}^{-1} \cdot \mathrm{L}\right)$ & $\Phi_{0}$ \\
\hline 1500 & $0.38 \pm 0.01$ & $(1.9 \pm 0.3) \cdot 10^{-2}$ & $(3.4 \pm 2.0) \cdot 10^{-3}$ \\
\hline 800 & $0.58 \pm 0.01$ & $(2.7 \pm 0.1) \cdot 10^{-2}$ & $(1.0 \pm 0.1) \cdot 10^{-2}$ \\
\hline 340 & $0.71 \pm 0.01$ & $(9.0 \pm 0.5) \cdot 10^{-2}$ & $(2.2 \pm 0.3) \cdot 10^{-2}$ \\
\hline 135 & $0.77 \pm 0.01$ & $(5.4 \pm 0.1) \cdot 10^{-1}$ & $(6.6 \pm 0.2) \cdot 10^{-2}$ \\
\hline 56 & $0.89 \pm 0.19$ & $(4.9 \pm 0.9) \cdot 10^{-1}$ & $0.18 \pm 0.03$ \\
\hline
\end{tabular}


Table 2

Summary of the effects on the open centers ratio of $\alpha$ (endogenous vs exogenous flows) and $\beta$ (electron transfer vs quinone transport kinetics) values.

\begin{tabular}{|c|c|c|c|c|c|}
\hline Zone & $\begin{array}{l}\text { Prevalent } \\
\text { flow }\end{array}$ & $\begin{array}{l}\text { Exogenous } \\
\text { flow r.d.s }\end{array}$ & $\Phi$ & $\begin{array}{l}\text { Dependance } \\
\text { on quinone } \\
\text { concentration? }\end{array}$ & Region \\
\hline 1 & $\begin{array}{l}\text { Endogenous } \\
\qquad(\alpha<1)\end{array}$ & $\begin{array}{l}\text { Electron } \\
\text { transfer } \\
(\beta<\alpha)\end{array}$ & $\Phi=\Phi_{0} \frac{\beta}{\alpha}=\frac{\Phi_{0} \Phi_{\infty}}{\rho_{0}} \frac{1}{C_{Q}}$ & $\begin{array}{l}\text { Yes } \\
\text { Decreasing } \\
\text { function }\end{array}$ & Inverted \\
\hline 2 & $\begin{array}{l}\text { Endogenous } \\
\qquad(\alpha<1)\end{array}$ & $\begin{array}{l}\text { Mass } \\
\text { transport } \\
(\beta>\alpha)\end{array}$ & $\Phi=\Phi_{0}$ & No & $\begin{array}{l}\text { Mainly } \\
\text { Normal }\end{array}$ \\
\hline 3 & $\begin{array}{l}\text { Exogenous } \\
\qquad(\alpha>1)\end{array}$ & $\begin{array}{l}\text { Electron } \\
\text { transfer } \\
(\beta<\alpha)\end{array}$ & $\Phi=\Phi_{0} \beta=\Phi_{\infty}$ & No & $\begin{array}{c}\text { Mainly } \\
\text { Inverted }\end{array}$ \\
\hline 4 & $\begin{array}{l}\text { Exogenous } \\
\qquad(\alpha>1)\end{array}$ & $\begin{array}{l}\text { Mass } \\
\text { transport } \\
(\beta>\alpha) \\
\end{array}$ & $\Phi=\Phi_{0} \alpha=\rho_{0} C_{Q}$ & $\begin{array}{c}\text { Yes } \\
\text { Increasing } \\
\text { function } \\
\end{array}$ & Normal \\
\hline 5 & Both & None & $\Phi=\Phi_{0} \frac{(1+\alpha) \beta}{(\alpha+\beta)}$ & Yes & Both \\
\hline 6 & Both & $\begin{array}{l}\text { Mass } \\
\text { transport } \\
(\beta>\alpha)\end{array}$ & $\Phi=\Phi_{0} \frac{(1+\alpha) \beta}{\beta}=\Phi_{0}+\rho_{0} C_{Q}$ & $\begin{array}{c}\text { Yes } \\
\text { Increasing } \\
\text { function } \\
\end{array}$ & Normal \\
\hline 7 & $\begin{array}{l}\text { Exogenous } \\
\qquad(\alpha>1)\end{array}$ & None & $\Phi=\Phi_{0} \frac{\alpha \beta}{(\alpha+\beta)}=\frac{\Phi_{\infty} C_{Q}}{\frac{\Phi_{\infty}}{\rho_{0}}+C_{Q}}$ & $\begin{array}{c}\text { Yes } \\
\text { Increasing } \\
\text { function }\end{array}$ & $\begin{array}{l}\text { Mainly } \\
\text { Normal }\end{array}$ \\
\hline 8 & $\begin{array}{l}\text { Endogenous } \\
\qquad(\alpha<1)\end{array}$ & None & $\Phi=\Phi_{0} \frac{\beta}{(\alpha+\beta)}=\frac{\Phi_{0} \Phi_{\infty}}{\Phi_{\infty}+\rho_{0} C_{Q}}$ & $\begin{array}{c}\text { Yes } \\
\text { Decreasing } \\
\text { function }\end{array}$ & $\begin{array}{l}\text { Mainly } \\
\text { Inverted }\end{array}$ \\
\hline 9 & Both & $\begin{array}{l}\text { Electron } \\
\text { transfer } \\
(\beta<\alpha) \\
\end{array}$ & $\Phi=\Phi_{0} \frac{(1+\alpha) \beta}{\alpha}=\Phi_{\infty}+\frac{\Phi_{\infty} \Phi_{0}}{\rho_{0}} \frac{1}{C_{Q}}$ & $\begin{array}{c}\text { Yes } \\
\text { Decreasing } \\
\text { function }\end{array}$ & Inverted \\
\hline
\end{tabular}




\section{Figure captions}

Figure 1. Simplified scheme of photosynthesis in the thylakoid membrane. The dashed line traces the endogenous electron flow along the photosynthetic electron transport chain. Abbreviations include Photosystems I and II (PSI and PSII), plastoquinone (PQ) and plastoquinol $\left(\mathrm{PQH}_{2}\right)$, cytochrome $\mathrm{b}_{6} \mathrm{f}\left(\mathrm{b}_{6} \mathrm{f}\right)$.

Figure 2. A typical fluorescence experiment demonstrating the photosynthetic electron extraction by exogenous quinones on mutant algae at $\mathrm{I}^{\circ}=135 \mu \mathrm{E} \cdot \mathrm{m}^{-2} \cdot \mathrm{s}^{-1}$ without any exogenous quinone (- solid line) or in presence of 2,6-DCBQ (30 $\mu \mathrm{M}$, --- dashed line). The fluorescence decrease ( $F_{\text {stat }}$ to $F_{\text {stat }}$ ') is due to quenching and extraction by the exogenous quinone. A subsequent surpersaturating light pulse rapidly closes all open centers than they can be reopened by the exogenous quinones leading to a fluorescence increase ( $F_{\text {stat }}$ 'to $F_{\max }$ ') allowing one to discriminate the fluorescence variations induced by quenching and extraction phenomena. In that way, the open reaction centers ratio can be deduced. Because no data was recorded during the saturated pulse ( $F_{\max }$ is only measured after the saturating pulse, see experimental part), the discontinuity is indicated with open circles.

Figure 3. A) Simplified scheme of electron transfers occurring in Photosystem II to plastoquinone pool. After excitation, the reaction center P680 induces water oxidation by the Oxygen Evolving Complex (OEC). P680 also reduces the primary acceptor $\mathrm{Q}_{\mathrm{A}}$ by way of pheophytin (pheo). The electron is then transferred to a plastoquinone (PQ) bounds in the $\mathrm{Q}_{\mathrm{B}}$ pocket. B) Scheme of open and closed centers of Photosystem II after a proper excitation of P680.

Figure 4. Open centers ratio $\Phi$ as a function of the available 2,6-DCBQ concentration $\mathrm{C}_{\mathrm{Q}}$ for five light intensities (56; 135; 340; 800 and $\left.1500 \mu \mathrm{E} \cdot \mathrm{m}^{-2} . \mathrm{s}^{-1}\right)$.

Figure 5. A) Scheme showing competition for photosynthetic electrons between the exogenous quinone $\mathrm{Q}$ and the endogenous $\mathrm{PQ}$. The midpotential values are given for $\mathrm{Q}_{\mathrm{A}}, \mathrm{Q}$ (in the case of 2,6-DCBQ) and PQ. B) Detailed representation of the suggested extraction mechanism. 
Figure 6. Inverse of the open reaction centers ratio in absence of exogenous quinones $\left(1 / \Phi_{0}\right)$ as a function of the incident light intensity for mutant algae.

Figure 7. Inverse of the maximum open reaction centers ratio $\left(1 / \Phi_{\infty}\right)$ as a function of the incident light intensity in presence of 2,6-DCBQ for mutant (white circles) and wild-type (filled circles) algae.

Figure 8. $\operatorname{Ln}\left(\left(1 / \Phi_{\infty}\right)-1\right)$ parameter as a function of the $E_{Q}-E_{Q A}$ term (see text) for experiments $\left(\mathrm{I}^{\circ}=340 \mu \mathrm{E} \cdot \mathrm{m}^{-2} . \mathrm{s}^{-1}\right)$ involving four exogenous quinones (NBQ, PPBQ, 2,5DCBQ and 2,6-DCBQ)

Figure 9. Zone diagram of the open center ratio as a function of $\alpha$ and $\beta$ parameters (see text). The vertical yellow line correspond to the frontier between inverted $(\beta<1)$ and normal $(\beta>1)$ regions. Nine main zones (1-9) were thus defined if considering red and orange solid lines. Orange solid lines correspond to frontiers from which one of the fluxes can be neglected (less than 10\%). Red solid lines correspond to frontiers from which fluxes can be simplified by neglecting one of the kinetics limitations. Dashed lines allow one to define sub-zones. The dashed orange line corresponds to equal endogenous and exogenous fluxes. The red dashed line is related to conditions for which the exogenous flux is equally both rate-determined by electron transfer and the quinone arrival.

Figure 10. Open centers ratio $\Phi$ as a function of the available NQ concentration $C_{Q}\left(I^{\circ}=135\right.$ $\mu \mathrm{E} \cdot \mathrm{m}^{-2} \cdot \mathrm{s}^{-1}$ ) in the case of wild-type algae (white circles) and mutant algae (filled circles).

Figure 11. Zone diagram of the open center ratio as a function of quinone concentration $C_{Q}$ and incident light $I^{\circ}$. The frontiers and the zones numbers are already defined in the Figure 9 legend. 
Supporting Information

Mechanism and Analyses for Extracting Photosynthetic Electrons using Exogenous Quinones - What Makes a Good Extraction Pathway?

Guillaume Longatte, Fabrice Rappaport, Francis-André Wollman, Manon Guille-Collignon, Frédéric Lemaître 


\section{Typical experiment with wild type algae}

While experiments of photosynthetic electrons are performed with mutant algae, the same kind of analyses can be achieved on wild-type algae, i.e. with $b_{6} f$ complex. In this case, due to a higher endogenous flow if compared to mutant algae, the light intensities used have to be larger to observe a significant variation of the open centers ratio in presence of quinone. Therefore, three light intensities were investigated (340, 800 and $1500 \mu \mathrm{E} \cdot \mathrm{m}^{-2} . \mathrm{s}^{-1}$ ). An example of fluorescence measurements is depicted in Figure S1.

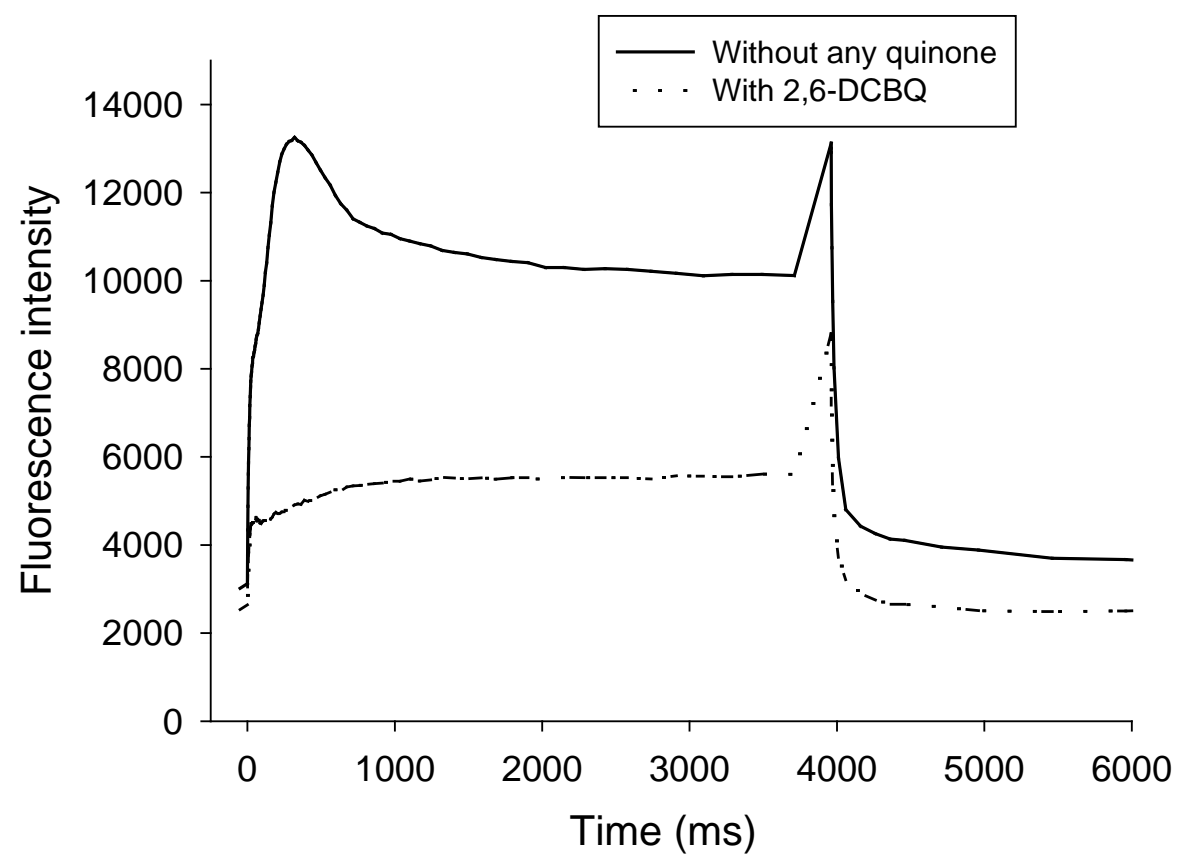

Figure S1. A typical fluorescence experiment demonstrating the photosynthetic electron extraction on wild-type algae by exogenous quinones at $\mathrm{I}^{\circ}=800 \mu \mathrm{E} \cdot \mathrm{m}^{-2} \cdot \mathrm{s}^{-1}$ without any exogenous quinone (- solid line) or in presence of 2,6-DCBQ (50 $\mu \mathrm{M}$, --- dashed line).

It has to be emphasized that the whole shapes of the fluorescence curves are quite similar to those obtained with mutant algae. However, without any quinone addition, a transient increase of the fluorescence level is observed before reaching the usual steady-state value. Such behaviour may be related to the fast reduction of the PSII acceptor (that leads to the fluorescence increase) before its subsequent oxidation by downstream electron acceptors in the photosynthetic chain (that decreases the number of closed centers and thus the fluorescence level) until reaching a steady state. The decrease from the initial maximum is likely not observed in the mutant due to the very low endogenous flow. The presence of exogenous quinones as electrons acceptors prevents the initial fluorescence increase. 
2. Supplementary data for the extraction mechanism with 2,6-DCBQ

a) Reduction of equations 4-7 to Equation 8

The equations to consider are :

$$
\begin{aligned}
& F(I)\left[Q_{A}\right]+k_{-Q}\left[Q Q_{A}^{-}\right]=\left(k_{\text {endo }}+C_{Q} k_{Q}\right)\left[Q_{A}^{-}\right] \\
& k_{-e}\left[Q^{-} Q_{A}\right]+k_{Q} C_{Q}\left[Q_{A}^{-}\right]=\left(k_{e}+k_{-Q}\right)\left[Q Q_{A}^{-}\right] \\
& k_{e}\left[Q Q_{A}^{-}\right]=\left(k_{-e}+k_{d Q}\right)\left[Q^{-} Q_{A}\right] \\
& {\left[Q_{A}\right]+\left[Q_{A}^{-}\right]+\left[Q Q_{A}^{-}\right]+\left[Q^{-} Q_{A}\right]=1}
\end{aligned}
$$

(S3) gives to

$$
\left[Q^{-} Q_{A}\right]=\frac{k_{e}}{\left(k_{-e}+k_{d Q}\right)}\left[Q Q_{A}^{-}\right]
$$

By inserting (S5) in (S2) one has :

$$
\begin{aligned}
& k_{-e} \frac{k_{e}}{\left(k_{-e}+k_{d Q}\right)}\left[Q Q_{A}^{-}\right]+k_{Q} C_{Q}\left[Q_{A}^{-}\right]=\left(k_{e}+k_{-Q}\right)\left[Q Q_{A}^{-}\right] \\
& k_{Q} C_{Q}\left[Q_{A}^{-}\right]=\left(\left(k_{e}+k_{-Q}\right)-k_{-e} \frac{k_{e}}{\left(k_{-e}+k_{d Q}\right)}\right)\left[Q Q_{A}^{-}\right] \\
& {\left[Q Q_{A}^{-}\right]=\left[Q_{A}^{-}\right] \frac{k_{Q} C_{Q}\left(k_{-e}+k_{d Q}\right)}{\left(k_{e}+k_{-Q}\right)\left(k_{-e}+k_{d Q}\right)-k_{e} k_{-e}}} \\
& {\left[Q Q_{A}^{-}\right]=\left[Q_{A}^{-}\right] \frac{k_{Q} C_{Q}\left(k_{-e}+k_{d Q}\right)}{k_{-Q}\left(k_{-e}+k_{d Q}\right)+k_{e} k_{d Q}}}
\end{aligned}
$$

By inserting (S6) in (S1) one obtains :

$$
\begin{gathered}
F(I)\left[Q_{A}\right]+k_{-Q} \frac{k_{Q} C_{Q}\left(k_{-e}+k_{d Q}\right)}{k_{-Q}\left(k_{-e}+k_{d Q}\right)+k_{e} k_{d Q}}\left[Q_{A}^{-}\right]=\left(k_{\text {endo }}+C_{Q} k_{Q}\right)\left[Q_{A}^{-}\right] \\
{\left[Q_{A}^{-}\right]=F(I) \frac{k_{-Q}\left(k_{-e}+k_{d Q}\right)+k_{e} k_{d Q}}{\left(k_{\text {endo }}+C_{Q} k_{Q}\right)\left(k_{-Q}\left(k_{-e}+k_{d Q}\right)+k_{e} k_{d Q}\right)-k_{-Q} k_{Q} C_{Q}\left(k_{-e}+k_{d Q}\right)}\left[Q_{A}\right]} \\
{\left[Q_{A}^{-}\right]=F(I) \frac{k_{-Q}\left(k_{-e}+k_{d Q}\right)+k_{e} k_{d Q}}{k_{\text {endo }}\left(k_{-Q}\left(k_{-e}+k_{d Q}\right)+k_{e} k_{d Q}\right)+C_{Q} k_{Q} k_{e} k_{d Q}}\left[Q_{A}\right]}
\end{gathered}
$$


Combining (S7) to (S6) gives :

$$
\left[Q Q_{A}^{-}\right]=F(I) \frac{k_{Q} C_{Q}\left(k_{-e}+k_{d Q}\right)}{k_{\text {endo }}\left(k_{-Q}\left(k_{-e}+k_{d Q}\right)+k_{e} k_{d Q}\right)+C_{Q} k_{Q} k_{e} k_{d Q}}\left[Q_{A}\right]
$$

Combining (S8) to (S5) gives :

$$
\left[Q^{-} Q_{A}\right]=F(I) \frac{k_{e} k_{Q} C_{Q}}{k_{\text {endo }}\left(k_{-Q}\left(k_{-e}+k_{d Q}\right)+k_{e} k_{d Q}\right)+C_{Q} k_{Q} k_{e} k_{d Q}}\left[Q_{A}\right]
$$

Inserting (S7), (S8) and (S9) to (S4) gives:

$$
\begin{aligned}
& {\left[Q_{A}\right]+F(I) \frac{k_{-Q}\left(k_{-e}+k_{d Q}\right)+k_{e} k_{d Q}}{k_{\text {endo }}\left(k_{-Q}\left(k_{-e}+k_{d Q}\right)+k_{e} k_{d Q}\right)+C_{Q} k_{Q} k_{e} k_{d Q}}\left[Q_{A}\right]} \\
& +F(I) \frac{k_{Q} C_{Q}\left(k_{-e}+k_{d Q}\right)}{k_{\text {endo }}\left(k_{-Q}\left(k_{-e}+k_{d Q}\right)+k_{e} k_{d Q}\right)+C_{Q} k_{Q} k_{e} k_{d Q}}\left[Q_{A}\right] \\
& +F(I) \frac{k_{e} k_{Q} C_{Q}}{k_{\text {endo }}\left(k_{-Q}\left(k_{-e}+k_{d Q}\right)+k_{e} k_{d Q}\right)+C_{Q} k_{Q} k_{e} k_{d Q}}\left[Q_{A}\right]=1 \\
& \frac{k_{\text {endo }}\left(k_{-Q}\left(k_{-e}+k_{d Q}\right)+k_{e} k_{d Q}\right)+C_{Q} k_{Q} k_{e} k_{d Q}}{k_{\text {endo }}\left(k_{-Q}\left(k_{-e}+k_{d Q}\right)+k_{e} k_{d Q}\right)+C_{Q} k_{Q} k_{e} k_{d Q}}+ \\
& \frac{F(I)\left(k_{-Q}\left(k_{-e}+k_{d Q}\right)+k_{e} k_{d Q}\right)+F(I) k_{Q} C_{Q}\left(k_{-e}+k_{d Q}\right)+F(I) k_{e} k_{Q} C_{Q}}{k_{\text {endo }}\left(k_{-Q}\left(k_{-e}+k_{d Q}\right)+k_{e} k_{d Q}\right)+C_{Q} k_{Q} k_{e} k_{d Q}}=\frac{1}{\left[Q_{A}\right]} \\
& \frac{\left(k_{\text {endo }}+F(I)\right)\left(k_{-Q}\left(k_{-e}+k_{d Q}\right)+k_{e} k_{d Q}\right)+C_{Q} k_{Q}\left(k_{e} k_{d Q}+F(I)\left(k_{-e}+k_{d Q}+k_{e}\right)\right)}{k_{\text {endo }}\left(k_{-Q}\left(k_{-e}+k_{d Q}\right)+k_{e} k_{d Q}\right)+C_{Q} k_{Q} k_{e} k_{d Q}}=\frac{1}{\left[Q_{A}\right]}
\end{aligned}
$$

One finally has :

$$
\Phi=\left[Q_{A}\right]=\frac{k_{\text {endo }}\left(k_{-Q}\left(k_{-e}+k_{d Q}\right)+k_{d Q} k_{e}\right)+k_{Q} k_{d Q} k_{e} C_{Q}}{\left(k_{\text {endo }}+F(I)\right)\left(k_{-Q}\left(k_{-e}+k_{d Q}\right)+k_{d Q} k_{e}\right)+k_{Q} C_{Q}\left(F(I)\left(k_{e}+k_{-e}+k_{d Q}\right)+k_{d Q} k_{e}\right)}
$$

This equation well corresponds to equation (8) in the text. 
b) Additional validation of the mechanism

As demonstrated in the article, the open centers ratio $\Phi$ can be defined according to two equations. Equation (S12) is deduced from the experimental data :

$$
\Phi=\frac{\Phi_{0} \frac{\Phi_{\infty}}{\rho_{0}}+\Phi_{\infty} C_{Q}}{\frac{\Phi_{\infty}}{\rho_{0}}+C_{Q}}
$$

Equation (S11) results from the extraction mechanism considered and demonstrated above:

$$
\Phi=\frac{k_{\text {endo }}\left(k_{-Q}\left(k_{-e}+k_{d Q}\right)+k_{d Q} k_{e}\right)+k_{Q} k_{d Q} k_{e} C_{Q}}{\left(k_{\text {endo }}+F(I)\right)\left(k_{-Q}\left(k_{-e}+k_{d Q}\right)+k_{d Q} k_{e}\right)+k_{Q} C_{Q}\left(F(I)\left(k_{e}+k_{-e}+k_{d Q}\right)+k_{d Q} k_{e}\right)}
$$

It thus helps to extract peculiar quantities as the initial slope of the exogenous flow part of the $\Phi=\mathrm{f}\left(\mathrm{C}_{\mathrm{Q}}\right)$ curve $\left(\rho_{0}\right)$.

$$
\rho_{0}=\frac{k_{Q} k_{d Q} k_{e}}{\left(k_{\text {endo }}+F(I)\right)\left(k_{-Q}\left(k_{-e}+k_{d Q}\right)+k_{d Q} k_{e}\right)}
$$

Thus, it leads to:

$$
\frac{1}{\rho_{0}}=\frac{k_{\text {endo }}\left(k_{-Q}\left(k_{-e}+k_{d Q}\right)+k_{d Q} k_{e}\right)}{k_{Q} k_{d Q} k_{e}}+\frac{\left(k_{-Q}\left(k_{-e}+k_{d Q}\right)+k_{d Q} k_{e}\right)}{k_{Q} k_{d Q} k_{e}} F(I)
$$

Figure S2 thus shows a linear dependence between $1 / \rho_{0}$ and $I^{\circ}$ values and consequently strengthening the mechanism considered in the present work. 


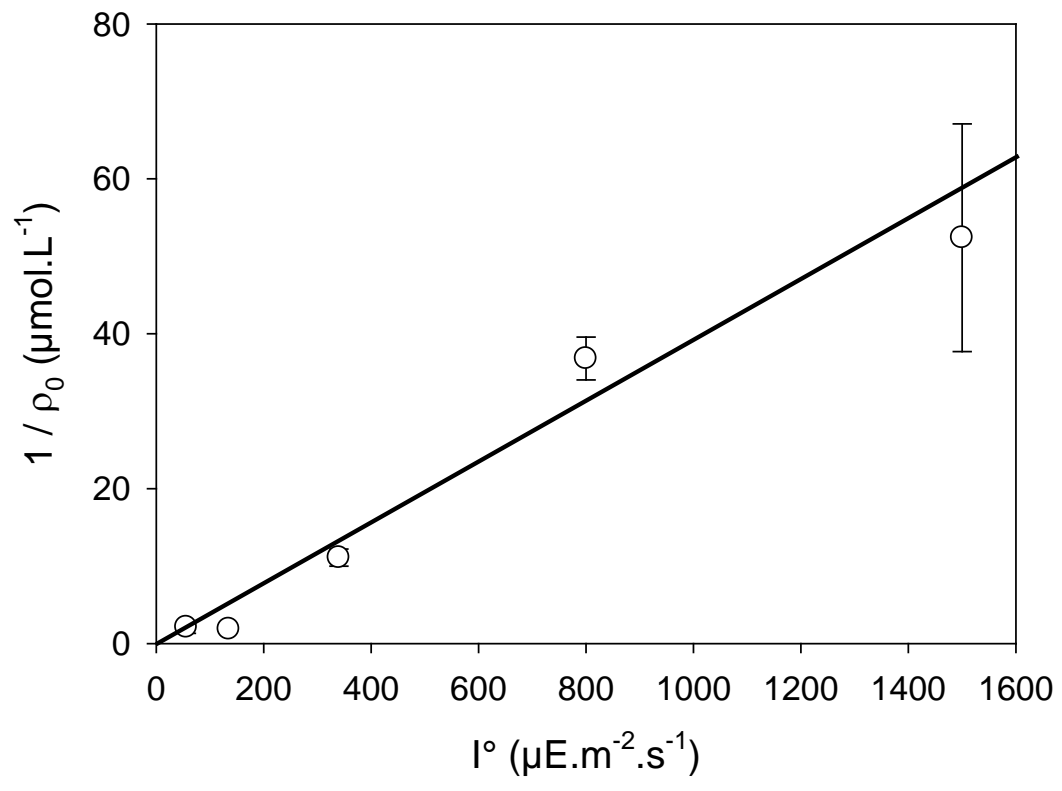

Figure S2. Inverse of $\rho_{0}$ (initial slope of the $\Phi=f\left(C_{Q}\right)$ curves described in Figure 4) as a function of the incident light intensity for mutant algae.

3. Zone diagrams : derivation of equations (15), (16) and (17)

Equation (2) in the article (or (S12) in the supporting information) gives access to the open centers ratio and can be written as according to :

$$
\Phi=\frac{\Phi_{0} \frac{\Phi_{\infty}}{\rho_{0}}+\Phi_{\infty} C_{Q}}{\frac{\Phi_{\infty}}{\rho_{0}}+C_{Q}}=\frac{\Phi_{0}+\rho_{0} C_{Q}}{1+\frac{\rho_{0}}{\Phi_{\infty}} C_{Q}}
$$

Therefore the left part of the numerator is related to the endogenous flux $\left(\Phi_{0}\right)$ and the right part to the $C_{Q}$-dependent extraction by the exogenous flux $\left(\rho_{0} C_{Q}\right)$. The ratio between the right and left parts of the numerator thus corresponds to the ratio (named $\alpha$ ) between exogenous and endogenous fluxes. Due to the extraction mechanism considered, equation (2) corresponds to equation (8) in the article (or (S11) in the supporting information):

$$
\Phi=\frac{k_{\text {endo }}\left(k_{-Q}\left(k_{-e}+k_{d Q}\right)+k_{d Q} k_{e}\right)+k_{Q} k_{d Q} k_{e} C_{Q}}{\left(k_{\text {endo }}+F(I)\right)\left(k_{-Q}\left(k_{-e}+k_{d Q}\right)+k_{d Q} k_{e}\right)+k_{Q} C_{Q}\left(F(I)\left(k_{e}+k_{-e}+k_{d Q}\right)+k_{d Q} k_{e}\right)}
$$


Therefore, one obtains the following equation (numbered 15 in the article):

$$
\alpha=\frac{k_{Q} k_{d Q} k_{e} C_{Q}}{k_{\text {endo }}\left(k_{-Q}\left(k_{-e}+k_{d Q}\right)+k_{d Q} k_{e}\right)}
$$

Moreover, if considering equation (S11), one has:

$$
\Phi=\frac{k_{\text {endo }}\left(k_{-Q}\left(k_{-e}+k_{d Q}\right)+k_{d Q} k_{e}\right)\left(1+\frac{k_{Q} k_{d Q} k_{e} C_{Q}}{\left.k_{\text {endo }}\left(k_{-Q}\left(k_{-e}+k_{d Q}\right)+k_{d Q} k_{e}\right)\right)}\right)}{\left(k_{-Q}\left(k_{-e}+k_{d Q}\right)+k_{d Q} k_{e}\right)\left(\left(k_{\text {endo }}+F(I)\right)+\frac{k_{Q} C_{Q}\left(F(I)\left(k_{e}+k_{-e}+k_{d Q}\right)+k_{d Q} k_{e}\right)}{\left(k_{-Q}\left(k_{-e}+k_{d Q}\right)+k_{d Q} k_{e}\right)}\right)}
$$

By inserting equation (S15) in (S16), one gets :

$$
\Phi=\frac{k_{\text {endo }}(1+\alpha)}{\left(\left(k_{\text {endo }}+F(I)\right)+\frac{k_{Q} C_{Q}\left(F(I)\left(k_{e}+k_{-e}+k_{d Q}\right)+k_{d Q} k_{e}\right)}{\left(k_{-Q}\left(k_{-e}+k_{d Q}\right)+k_{d Q} k_{e}\right)}\right)}
$$

Furthermore, equation (S17) becomes :

$$
\Phi=\frac{k_{\text {endo }}(1+\alpha)}{\left(\left(k_{\text {endo }}+F(I)\right)+\frac{k_{Q} k_{d Q} k_{e} C_{Q}}{k_{\text {endo }}\left(k_{-Q}\left(k_{-e}+k_{d Q}\right)+k_{d Q} k_{e}\right)} k_{\text {endo }}\left(\frac{F(I)\left(k_{e}+k_{-e}+k_{d Q}\right)}{k_{d Q} k_{e}}+1\right)\right)}
$$

By inserting equation (S15) in (S18), one gets equation (S19) that corresponds to equation (16) in the manuscript:

$$
\Phi=\frac{k_{\text {endo }}(1+\alpha)}{\left(k_{\text {endo }}+F(I)\right)+\alpha k_{\text {endo }}\left(\frac{F(I)\left(k_{e}+k_{-e}+k_{d Q}\right)}{k_{d Q} k_{e}}+1\right)}
$$

The exogenous flux is due to the extraction by the exogenous quinone $\mathrm{Q}$ and can be ratedetermined by the exogenous quinone $\mathrm{Q}$ insertion within the $\mathrm{Q}_{\mathrm{B}}$ pocket or the subsequent electron transfer between $\mathrm{Q}$ and $\mathrm{Q}_{\mathrm{A}}$ (the free quinone concentration term of the denominator). The prevalence of each is expected to play a role on the denominator of equation (S11). Indeed, according to the model, if exogenous flow prevails, a mass transfer controlled process should be quinone concentration dependent while it will be not the case if the process is rate- 
determined by the electron transfer step. According to equation (S11), if exogenous flow prevails, one has :

$$
\Phi=\frac{k_{Q} k_{d Q} k_{e} C_{Q}}{\left(k_{\text {endo }}+F(I)\right)\left(k_{-Q}\left(k_{-e}+k_{d Q}\right)+k_{d Q} k_{e}\right)+k_{Q} C_{Q}\left(F(I)\left(k_{e}+k_{-e}+k_{d Q}\right)+k_{d Q} k_{e}\right)}
$$

Therefore, the $C_{Q}$ dependence of $\Phi$ within the exogenous flow expression will be related to the comparison between $k_{Q} C_{Q}\left(F(I)\left(k_{e}+k_{-e}+k_{d Q}\right)+k_{d Q} k_{e}\right) \quad$ and $\left(k_{\text {endo }}+F(I)\right)\left(k_{-Q}\left(k_{-e}+k_{d Q}\right)+k_{d Q} k_{e}\right)$. This consists in fact to compare $\alpha k_{\text {endo }}\left(\frac{F(I)\left(k_{e}+k_{-e}+k_{d Q}\right)}{k_{d Q} k_{e}}+1\right)$ and $k_{\text {endo }}+F(I)$ in equation (S19). This is why a new parameter (named $\beta$ ) can be defined :

$$
\beta=\frac{k_{\text {endo }}+F(I)}{k_{\text {endo }}\left(\frac{F(I)\left(k_{e}+k_{-e}+k_{d Q}\right)}{k_{d Q} k_{e}}+1\right)}
$$

$\beta$ is thus a specific $\alpha$ value corresponding to the equality between quinone insertion and electron transfer rates. Therefore, the electron transfer rate will be higher than the insertion if $\alpha<<\beta$.

Moreover, equation (S19) can be written as:

$$
\Phi=\frac{k_{\text {endo }}(1+\alpha)}{\left(k_{\text {endo }}+F(I)\right)\left(1+\frac{\alpha k_{\text {endo }}}{\left(k_{\text {endo }}+F(I)\right)}\left(\frac{F(I)\left(k_{e}+k_{-e}+k_{d Q}\right)}{k_{d Q} k_{e}}+1\right)\right)}
$$

Inserting equation (S21) in equation (S22) gives:

$$
\Phi=\frac{k_{\text {endo }}(1+\alpha)}{\left(k_{\text {endo }}+F(I)\right)\left(1+\frac{\alpha}{\beta}\right)}=\frac{k_{\text {endo }} \beta(1+\alpha)}{\left(k_{\text {endo }}+F(I)\right)(\beta+\alpha)}
$$

Finally, by inserting the $\Phi_{0}$ expression (equation (9) in the text) in equation (S23), one obtains:

$$
\Phi=\Phi_{0} \frac{(1+\alpha) \beta}{\alpha+\beta}
$$

Equation (S24) corresponds to equation (18) in the manuscript. 
4. Data treatment and analysis of the electron extraction on wild-type algae with exogenous quinones

Experiments concerning the effect of 2,6-DCBQ concentration were achieved with wild-type algae. As mentioned above, three light incident flows were considered. The results are depicted in Figure S3.

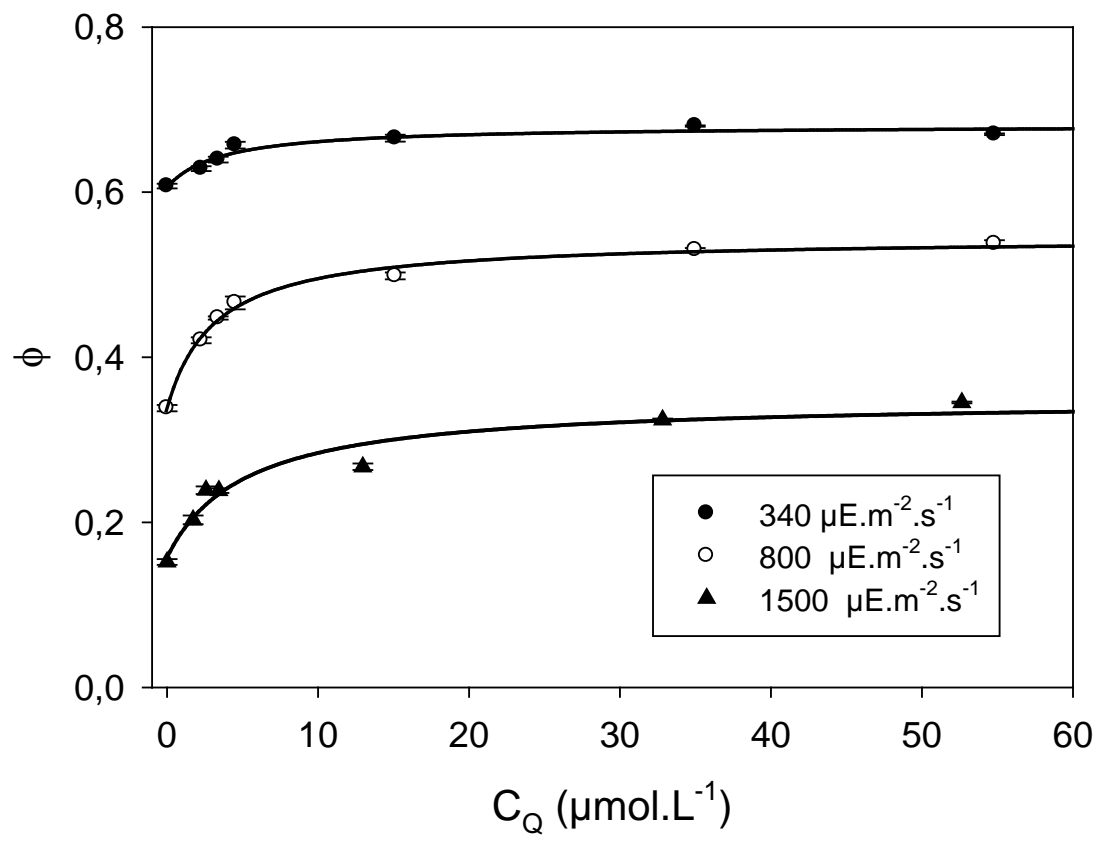

Figure S3. Open centers ratio $\Phi$ of a wild-type algae population as a function of the available

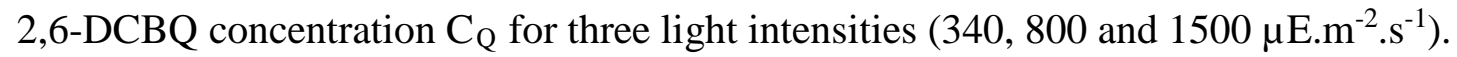

Hence, the $\Phi_{0}, \Phi_{\infty}$ and $\rho_{0}$ values can be extracted and are summarized in Table T1.

\begin{tabular}{|c|c|c|c|}
\hline $\mathrm{I}^{\circ}\left(\mu \mathrm{E} \cdot \mathrm{m}^{-2} . \mathrm{s}^{-1}\right)$ & $\Phi_{\infty}$ & $\rho_{0}\left(\mu \mathrm{mol}^{-1} . \mathrm{L}\right)$ & $\Phi_{0}$ \\
\hline 1500 & $0.37 \pm 0.01$ & $(5.2 \pm 2.0) \cdot 10^{-2}$ & $0.15 \pm 0.01$ \\
\hline 800 & $0.52 \pm 0.01$ & $(17 \pm 2) \cdot 10^{-2}$ & $0.34 \pm 0.01$ \\
\hline 340 & $0.68 \pm 0.01$ & $(21 \pm 15) .10^{-2}$ & $0.60 \pm 0.02$ \\
\hline
\end{tabular}

Table T1. Effect of the light intensity $\mathrm{I}^{\circ}$ on the extracted values reflecting the electron extraction induced by the exogenous 2,6-DCBQ addition $\left(\Phi_{\infty}\right.$ and $\left.\rho_{0}\right)$ and the open centers ratio in absence of exogenous quinones $\left(\Phi_{0}\right)$ for wild-type algae. 
It is worth mentioning that the same trends for $\Phi_{0}, \Phi_{\infty}$ and $\rho_{0}$ are observed in the case of wild-type algae in presence of exogenous 2,6-DCBQ if compared to mutant algae. It thus means that the inverted region can not be reached in this case although the endogenous flow is larger in wild-type algae. Particularly, it has to be emphasized that the $\Phi_{0}$ values are significantly higher for wild-type algae in accordance with a significant endogenous flow that already acts like an electron extraction pathway from the reduced state of PSII. It also supports outstandingly the mechanism suggested in the text because Equation (S7) is experimentally verified (see Figure S4):

$$
\frac{1}{\Phi_{0}}=1+\frac{F(I)}{k_{\text {endo }}}
$$

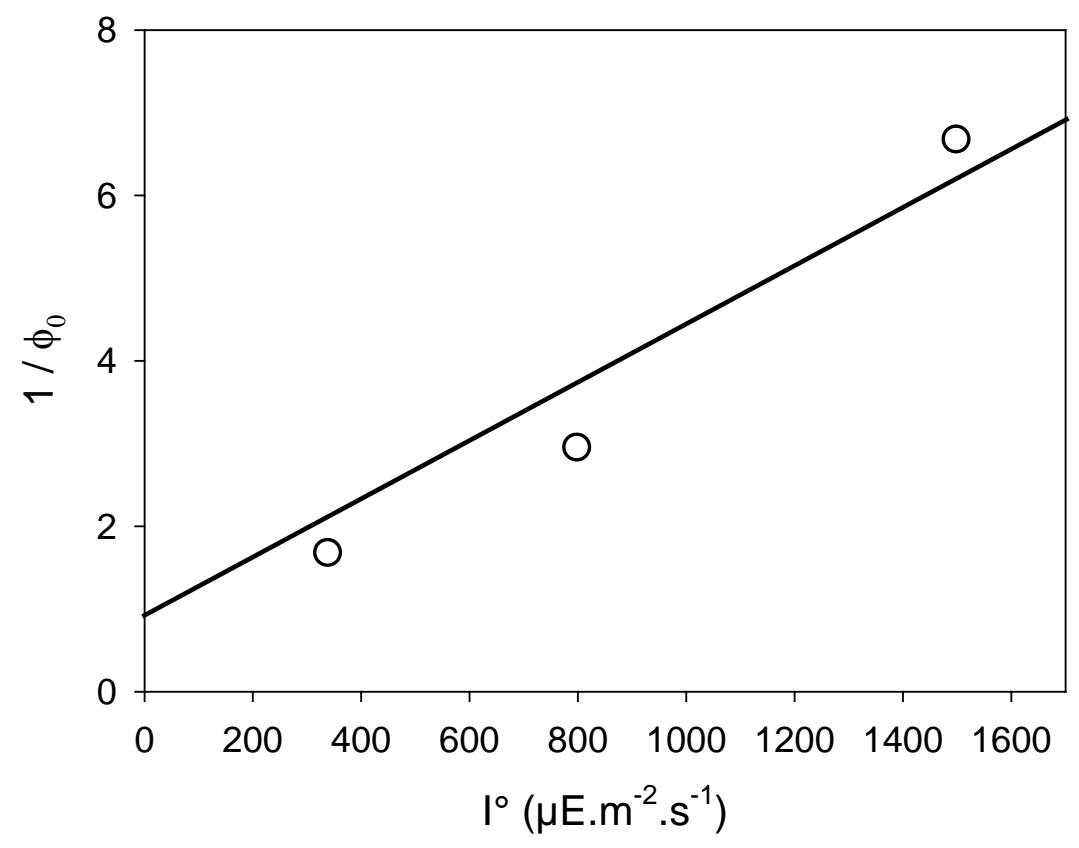

Figure S4. Inverse of the open reaction centers ratio in absence of exogenous quinones $\left(1 / \Phi_{0}\right)$ as a function of the incident light intensity for wild-type algae $\left(1 / \Phi_{0}=1+0.00364 \mathrm{I}^{\circ} ; \mathrm{R}^{2}=\right.$ $0.99)$.

The knowledge of these values as an incident light function let us to draw the same kind of zone diagram than for the mutant (see Figure S5). 


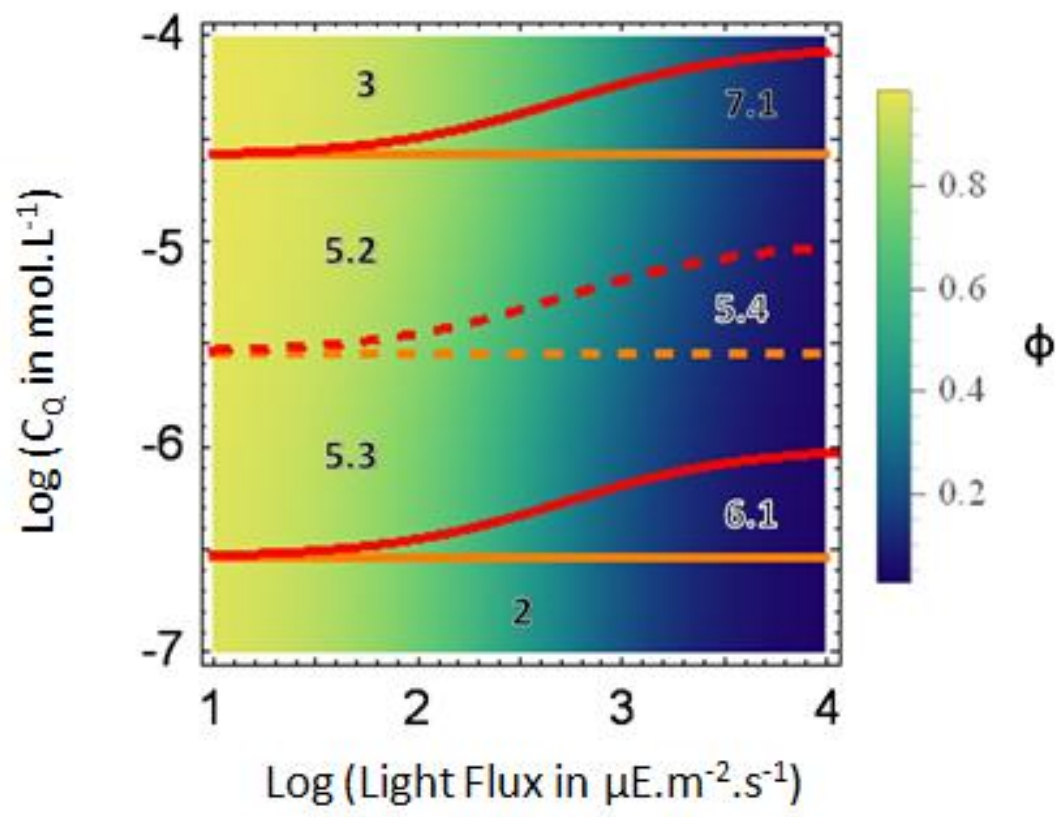

Figure S5. Zone diagram of the open center ratio as a function of quinone concentration $C_{Q}$ and incident light $\mathrm{I}^{\circ}$. Orange solid lines correspond to frontiers from which one of the fluxes can be neglected (within 10\%). Red solid lines correspond to frontiers from which fluxes or kinetics can be simplified (by neglecting one of the fluxes or one of the kinetics). Dashed lines allow one to define sub-zones. The dashed orange line corresponds to equal endogenous and exogenous fluxes. The red dashed line is related to conditions for which the exogenous flux is both rate-determined by electron transfer and the quinone arrival.

Remarkably all zones of open site ratio control described with the mutant in the article are still obtained for the wild type $(2,3,5,6,7)$. However, this is not the case for all the expected sub-zones in which both flows (cf zones 6.1 and 6.2) or both kinetics (cf zones 7.1 and 7.2) have to be considered together. Indeed, in the wild-type case, the zones 6.2 and 7.2 disappeared due to the increase of the endogenous flow. The fact that zone 6.2 lacks means that when the electron transfer kinetics limitation can be neglected due to a very low quinone concentration, endogenous flow is always (with this quinone/algae system) higher than exogenous one, while the latter can remain significant. Similarly, the fact that zone 7.2 lacks means that, when quinone concentration is so high that endogenous flow can be neglected, electron extraction is always more limited by electron transfer kinetics than by quinone insertion, while the latter cannot always be considered as infinitely fast. Therefore, such a zone diagram shows that it will be difficult to drastically increase the open site ratio without 
decreasing the endogenous flow with the 2,6-DCBQ-WT system. Hence, using wild type algae under conditions corresponding to zones 6.2 or 7.2 (in particular to work without organic matter in solution) and by assuming a term can be neglected in a sum if weighing lower than $10 \%$ of the other term, the appropriate exogenous quinone should lead to a $\left(\mathrm{QQ}_{\mathrm{A}^{-}}\right)^{-}$ state able to release its charge at least 10 times faster than $\left(\mathrm{Q}_{\mathrm{A}}{ }^{-}\right)$with endogenous flow. It means that $\beta$ must be $>10$ in order to observe this zone. In this case of the 2,6-DCBQ on wild type, a $\beta$ value of 3 is obtained. This is why the zones 6.2 and 7.2 are not observed here. Despite its high electron transfer rate compare to other quinones previously studied, using 2,6DCBQ with a wild type favors conditions too close to the inverted region.

5. Two electrons mechanism for the extraction by exogenous quinones

a. Description of the mechanism - Extraction of $\left(\Phi ; \Phi_{\infty} ; \Phi_{0} ; \underline{0}_{0}\right)$ parameters

The fact that quinones correspond to a bi-electronic system may lead to envision a two electrons mechanism for the extraction considered in the text. Because chloroquinones are known to have more affinity for the $\mathrm{Q}_{в}$ pocket than for the plastoquinone pool the following mechanism can be suggested.

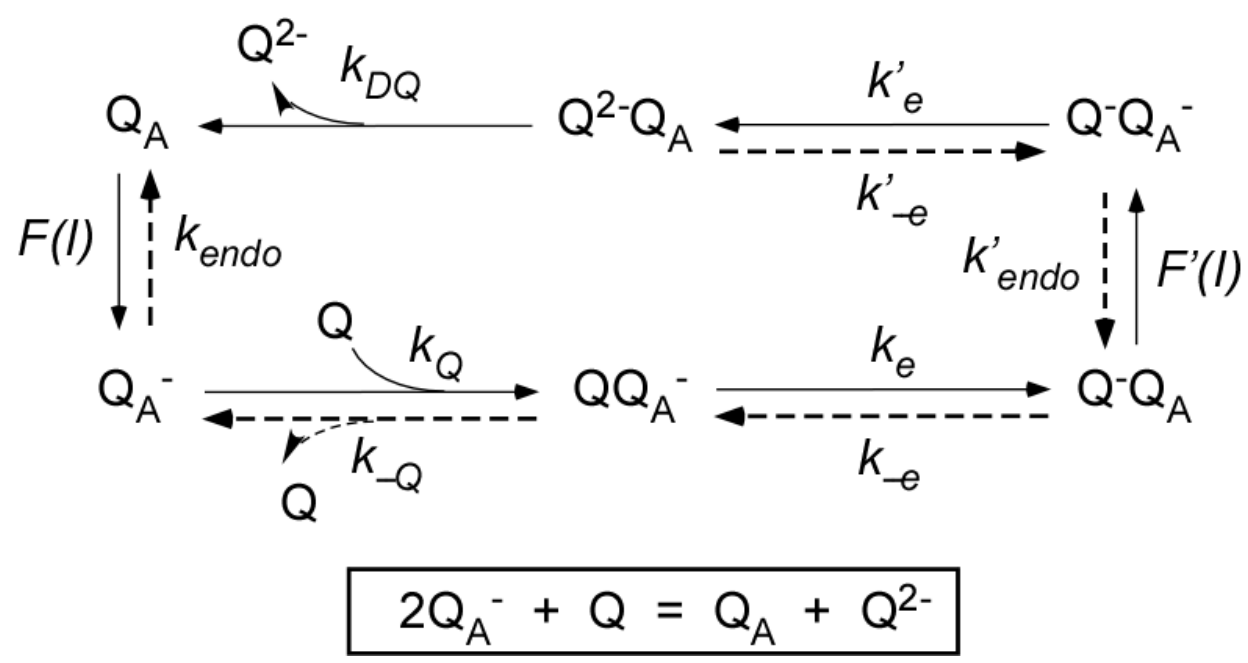

Briefly, the first steps of this mechanism can be compared to those of the simple one described in the text. Firstly, the exogenous quinone $\mathrm{Q}$ binds into $\mathrm{Q}_{\mathrm{B}}$ pocket and is followed by a first electron transfer step. However, the $\mathrm{Q}^{-} \mathrm{Q}_{\mathrm{A}}$ state formation is now followed by a second irradiation step which will reduce $\mathrm{Q}_{\mathrm{A}}$ and eventually lead to the full reduction of the exogenous quinone. 
Applying the quasi steady state approximation to intermediate states and summing all states in which $\mathrm{Q}_{\mathrm{A}}$ is oxidized will lead to open centers ratio according to :

$$
\Phi=\frac{k_{\text {endo }} B+A k_{Q} C_{Q}}{\left(k_{\text {endo }}+F(I)\right) B+k_{Q}\left(C_{1}+C_{2}\right) C_{Q}}
$$

With :

$$
\begin{aligned}
& B=k_{-e}^{\prime} k_{-e} k_{\text {endo }}^{\prime} k_{-Q}+k_{D Q} F^{\prime}(I) k_{e}^{\prime}\left(k_{-Q}+k_{e}\right)+k_{-Q} k_{-e}\left(k_{e n d o}^{\prime}+k_{e}^{\prime}\right) \\
& A=k_{e}\left(k_{D Q} F^{\prime}(I) k_{e}^{\prime}+F(I)\left(F^{\prime}(I) k_{e}^{\prime}+k_{\text {endo }}^{\prime}\left(k_{-e}^{\prime}+k_{D Q}\right)+k_{e}^{\prime} k_{D Q}\right)\right) \\
& C_{1}=F(I)\left(F^{\prime}(I)\left(k_{e}\left(k_{e}^{\prime}+k_{D Q}+k_{-e}^{\prime}\right)+k_{e}^{\prime} k_{D Q}\right)\right) \\
& C_{2}=F(I)\left(k_{-e}+k_{e}\right)\left(k_{\text {endo }}^{\prime}\left(k_{-e}^{\prime}+k_{D Q}\right)+k_{e}^{\prime} k_{D Q}\right)+k_{e} F^{\prime}(I) k_{e}^{\prime} k_{D Q}
\end{aligned}
$$

In comparison with the simple one electron mechanism, a similar dependence of $\Phi$ with the quinone concentration is obtained.

Moreover the three parameters extracted from the experiments can be calculated from equation (S11) :

$$
\begin{gathered}
\Phi_{0}=\frac{k_{\text {endo }}}{k_{\text {endo }}+F(I)} \\
\Phi_{\infty}=\frac{A}{C_{1}+C_{2}} \\
\rho_{0}=\frac{A k_{Q}}{\left(k_{\text {endo }}+F(I)\right) B}
\end{gathered}
$$

Expectedly the initial open centers ratio value (equation (S3)) is the same regardless of the applied mechanism (one electron or two electrons). The comparison for the $\Phi_{\infty}$ and $\rho_{0}$ parameters is more complicated and will be detailed below.

b. Analysis of the $\Phi_{\underline{0}} \underline{\text { parameter }}$

According to equation (S28), one has:

$$
\frac{1}{\Phi_{\infty}}=1+\frac{F^{\prime}(I)\left(k_{e}\left(k_{D Q}+k_{-e}^{\prime}\right)+k_{e}^{\prime} k_{D Q}\right)+k_{-e}\left(k_{\text {endo }}^{\prime}\left(k_{-e}^{\prime}+k_{D Q}\right)+k_{e}^{\prime} k_{D Q}\right.}{k_{e} F^{\prime}(I) k_{e}^{\prime}+k_{\text {endo }}^{\prime} k_{e}\left(k_{-e}^{\prime}+k_{D Q}\right)+k_{e} k_{e}^{\prime} k_{D Q}\left(1+\frac{F^{\prime}(I)}{F(I)}\right)}
$$


Experimental results (see Figure 7) showed that the $1 / \Phi_{\infty}=f\left(I^{\circ}\right)$ correspond to a linear relationship with an intercept value of 1 .

Assuming that both $\mathrm{F}(\mathrm{I})$ and $\mathrm{F}^{\prime}(\mathrm{I})$ are proportional to incident light flow $\mathrm{I}^{\circ}$, the experimental relationship between $1 / \Phi_{\infty}$ and $I^{\circ}$ means that the backward first electron transfer step can be neglected and that :

$$
F^{\prime}(I)<<k_{D Q}\left(1+\frac{F^{\prime}(I)}{F(I)}+\frac{k_{\text {endo }}^{\prime}}{k_{e}^{\prime}}\right)+\frac{k_{\text {endo }}^{\prime} k_{-e}^{\prime}}{k_{e}^{\prime}}
$$

Therefore one obtains:

$$
\frac{1}{\Phi_{\infty}}=1+\frac{F^{\prime}(I)\left(k_{e}\left(k_{D Q}+k_{-e}^{\prime}\right)+k_{e}^{\prime} k_{D Q}\right)}{k_{\text {endo }}^{\prime} k_{e}\left(k_{-e}^{\prime}+k_{D Q}\right)+k_{e} k_{e}^{\prime} k_{D Q}\left(1+\frac{F^{\prime}(I)}{F(I)}\right)}
$$

The observed dependence of $1 / \Phi_{\infty}$ with quinone midpoint potential (see Figure 8) suggests it should be controlled by electron transfer rate kinetics. Indeed, assuming $\mathrm{k}_{\mathrm{DQ}}>>\mathrm{k}^{\prime}$-e (according to the plastoquinone mechanism) and k' endo $<<\mathrm{k}^{\prime}$ е (due to а $\mathrm{Q}_{\text {в }}$ pocket filled by the exogenous quinone, all possible endogenous flows -plastoquinones, PETOX- are thus prevented except by charge recombination), $1 / \Phi_{\infty}$ can be rewritten as :

$$
\frac{1}{\Phi_{\infty}}=1+\frac{F^{\prime}(I) F(I)}{F^{\prime}(I)+F(I)} \frac{k_{e}+k_{-e}^{\prime}}{k_{e} k_{-e}^{\prime}}
$$

Equation (S32) evidenced that $1 / \Phi_{\infty}$ depends on the ratio of a global rate constant of two irradiation steps by a global rate constant of two electron transfer steps. From a mathematical point of view, it is worth to mention that the one electron mechanism globally gave a similar dependence between $1 / \Phi_{\infty}$ and the global incident light flow.

\section{c. Analysis of the $\rho_{0}$ parameter}

Using the same hypotheses than described above, $\rho_{0}$ can be expressed as :

$$
\rho_{0}=\frac{\Phi_{0} F(I)}{k_{\text {endo }} F^{\prime}(I)} \frac{k_{e} k_{Q}\left(k_{D Q} k_{e}^{\prime}\left(1+\frac{F^{\prime}(I)}{F(I)}\right)+k_{\text {endo }}^{\prime}\left(k_{-e}^{\prime}+k_{d Q}\right)\right.}{k_{e}^{\prime} k_{D Q}\left(k_{-Q}+k_{e}\right)}
$$


As in the one electron mechanism, the relation of proportionality between $\rho_{0}$ and $\Phi_{0}$ is still deduced.

\section{d. One electron vs two electron mechanism ?}

The two electrons mechanism also allows one to rationalize the experimental results and the dependence of the $\left(\Phi ; \Phi_{\infty} ; \Phi_{0} ; \rho_{0}\right)$ parameters with the quinone concentration or the incident light flow. However, it has to be emphasized that, despite a more simple formalism, the one electron mechanism is also consistent with experimental results. It therefore means that the expected complications resulting from the two electrons mechanism cannot be detected in the range of experimental conditions and sensitivity reported in this work.

It should be pointed out that the simple mechanism also allowed us to determine conditions in which the extraction was controlled by the quinone insertion (rate proportional to quinone concentration) or some electron transfer steps (whose rate does not depend on quinone concentration). Regardless of the mechanism, the similar dependence means that, in the range of the experimental conditions envisioned here, the built zone diagrams are not affected. The general zone diagram and its further conclusions remain not altered, even if the $\alpha$ and $\beta$ expressions obviously differ (see equations (S34) and (S35)).

$$
\begin{array}{r}
\alpha=\frac{C_{Q} k_{Q} A}{k_{\text {endo }} B} \\
\beta=\frac{k_{\text {endo }}+F(I)}{k_{\text {endo }}+k_{\text {endo }} \frac{C_{1}}{A}}
\end{array}
$$

The transition between normal and inverted zones still occurs for a $\beta$ value equal to 1 . In this case, the following parameter $\mathrm{P}$ is defined as :

$$
P=\frac{k_{\text {endo }}\left(k_{e}\left(k_{e}^{\prime}+k_{D Q}+k_{-e}^{\prime}\right)+\left(k_{e}^{\prime} k_{D Q}\right)\right.}{k_{e} k_{e}^{\prime} k_{D Q}\left(1+\frac{F(I)}{F^{\prime}(I)}\right)+\frac{F(I)}{F^{\prime}(I)} k_{e} k_{\text {endo }}^{\prime}\left(k_{-e}^{\prime}+k_{D Q}\right)}=1
$$

Assuming that $\mathrm{k}^{\prime}$ endo $<<\mathrm{k}_{\mathrm{e}}$ (see above) and $\mathrm{k}_{\mathrm{DQ}}>>\mathrm{k}_{\mathrm{e}}{ }_{\mathrm{e}}+\mathrm{k}^{\prime}{ }_{\mathrm{e}}$ (according to the plastoquinone reduction), equation (S36) becomes : 


$$
P=k_{\text {endo }} \frac{k_{e}+k_{e}^{\prime}}{k_{e} k_{e}^{\prime}} \frac{F^{\prime}(I)}{F(I)+F^{\prime}(I)}=1
$$

As in the simple mechanism, this $\mathrm{P}$ parameter still helps to compare endogenous flow and electron transfer. In the general case, it corresponds to the ratio between the $\mathrm{Q}_{\mathrm{A}}{ }^{-}$and $\mathrm{QQ}_{\mathrm{A}}{ }^{-}$ oxidation rate constants. As an example, a $\mathrm{P}$ value less than 1 corresponds to $\beta>1$ ). Therefore, $\mathrm{QQ}_{\mathrm{A}}{ }^{-}$release its charge faster than $\mathrm{QA}^{-}$that corresponds to a system work in a normal region in accordance with $\beta>1$.

6. Two electrons mechanism for the extraction by exogenous quinones

As mentioned in the article, the saturation pulse method is used to calculate the open centers ratio that is further modeled by an appropriate mechanism.

Such a pulse ( $\sim$ a few thousand $\mu \mathrm{E} \cdot \mathrm{m}^{-2} \cdot \mathrm{s}^{-1}$ during $250 \mathrm{~ms}$ ) corresponds to saturation conditions required to fully close the centers (and lead to the fluorescence value $F_{\max }$ ). In our case (Figure S6), the following experiment (in which the fluorescence is monitored during the pulse) shows that saturation readily occurs owing to the pulse. Indeed, the light intensity and pulse time course are appropriate since a fluorescence saturated level is already reached at around $180 \mathrm{~ms}$ after the pulse was triggered.

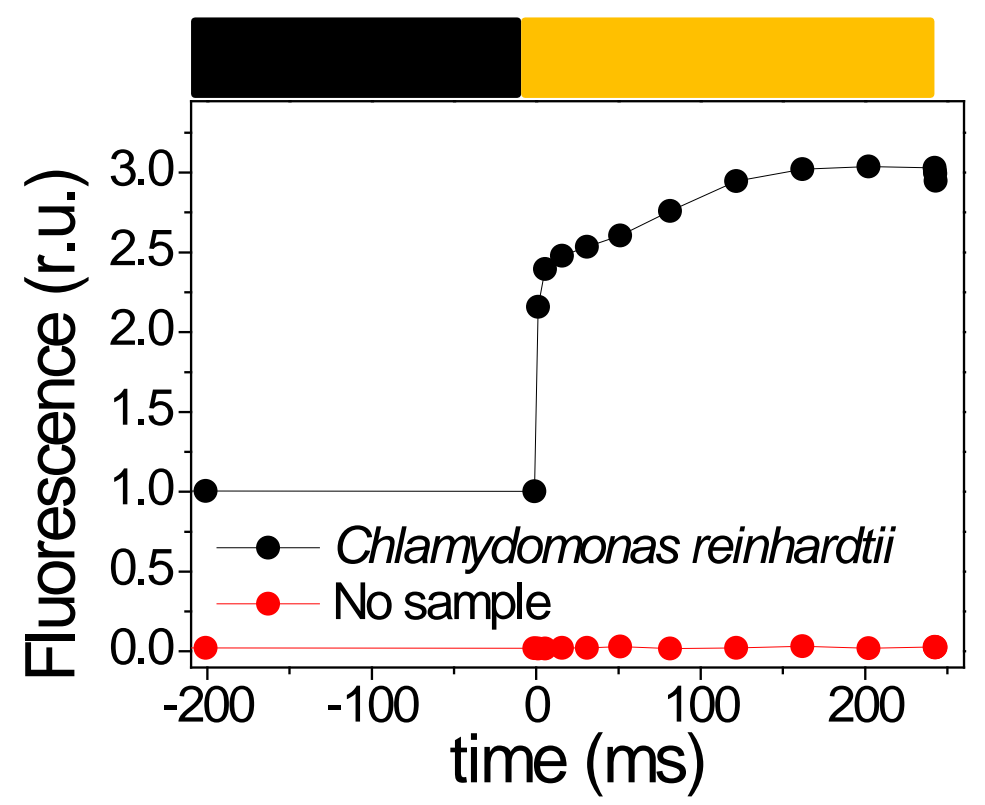

Figure S6. Real time fluorescence monitoring during the saturated pulse application (5000 $\left.\mu \mathrm{E} \cdot \mathrm{m}^{-2} . \mathrm{s}^{-1} ; 250 \mathrm{~ms}\right)$. The saturation is reached before the end of the pulse (that arbitrary starts at 0 in the graph). 